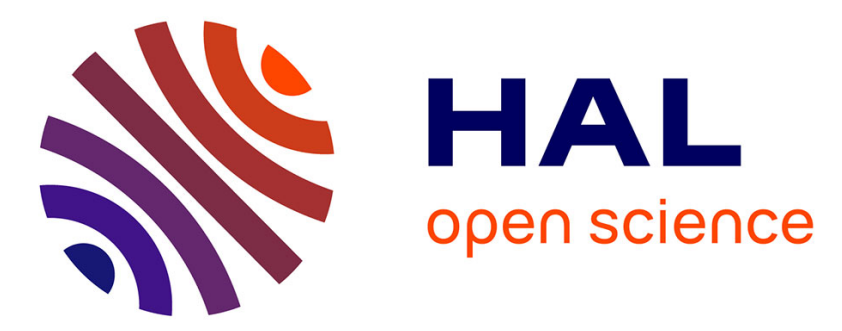

\title{
The impact of counterion on the metastable state properties of nitrosyl ruthenium complexes
}

Artem A Mikhailov, Vladislav Yu. Komarov, Aleksandr S Sukhikh, Denis P

Pishchur, Dominik Schaniel, Gennadiy A Kostin

\section{To cite this version:}

Artem A Mikhailov, Vladislav Yu. Komarov, Aleksandr S Sukhikh, Denis P Pishchur, Dominik Schaniel, et al.. The impact of counterion on the metastable state properties of nitrosyl ruthenium complexes. New Journal of Chemistry, 2020, 44 (41), pp.18014-18024. 10.1039/D0NJ04436A . hal02981047

\section{HAL Id: hal-02981047 \\ https://hal.univ-lorraine.fr/hal-02981047}

Submitted on 27 Oct 2020

HAL is a multi-disciplinary open access archive for the deposit and dissemination of scientific research documents, whether they are published or not. The documents may come from teaching and research institutions in France or abroad, or from public or private research centers.
L'archive ouverte pluridisciplinaire HAL, est destinée au dépôt et à la diffusion de documents scientifiques de niveau recherche, publiés ou non, émanant des établissements d'enseignement et de recherche français ou étrangers, des laboratoires publics ou privés.

\section{(ㅇ)(1) $\$$}

Distributed under a Creative Commons Attribution - NonCommerciall 4.0 International 


\section{The impact of counterion on metastable states properties in nitrosyl ruthenium complexes}

Artem A. Mikhailov*a, Vladislav Yu. Komarova, Aleksandr S. Sukhikhª, Denis P. Pishchura, Dominik Schaniel ${ }^{b}$ and Gennadiy A. Kostin ${ }^{a}$

a Nikolaev Institute of Inorganic Chemistry, Siberian Branch of the Russian Academy of Sciences, 3 Acad. Lavrentiev Avenue, Novosibirsk 630090, Russian Federation

b Université de Lorraine, CNRS, CRM2, UMR 7036, Nancy 54000, France

\section{Abstract}

In the present study four new complexes of the trans-[RuNO $\left.\left(\mathrm{NH}_{3}\right)_{4} \mathrm{~F}\right]^{2+}$ cation with noble-metal anions $\left[\mathrm{PtCl}_{6}\right]^{2-},\left[\mathrm{PdCl}_{4}\right]^{2-}$ and $\left[\mathrm{PtCl}_{4}\right]^{2-}$, and perchlorate anion $\mathrm{ClO}_{4}{ }^{-}$were synthesized and characterized by spectroscopic (IR, UV/vis), calorimetric (DSC) and single crystal X-Ray diffraction methods. All three complexes with the platinum and palladium cations crystallize in a non-centrosymmetric structure, which is determined by $\mathrm{N}-\mathrm{H} \cdots$ Halogen intermolecular interactions. The irradiation of the complexes by light in the spectral range of 300-420 nm induces Ru-ON isomers MS1, and the subsequent irradiation of MS1 in trans-[RuNO $\left.\left(\mathrm{NH}_{3}\right)_{4} \mathrm{~F}\right]\left(\mathrm{ClO}_{4}\right)_{2}$ by $940 \mathrm{~nm}$ light results in $\mathrm{Ru}-\left(\mathrm{n}^{2}-(\mathrm{NO})\right.$ isomer MS2 formation, which were detected by IR and UV/vis- spectroscopy. For trans-[RuNO$\left.\left(\mathrm{NH}_{3}\right)_{4} \mathrm{~F}\right]\left(\mathrm{ClO}_{4}\right)_{2}$ and trans$\left[\mathrm{RuNO}\left(\mathrm{NH}_{3}\right)_{4} \mathrm{~F}\right]\left[\mathrm{PdCl}_{4}\right]$ the activation energy $\left(\mathrm{E}_{\mathrm{a}}\right)$ and frequency factors (Igk $)$ of the MS1 $\rightarrow \mathrm{GS}$ transformation were determined, which are $104(1) \mathrm{kJ} \mathrm{mol}^{-1}$ and $15.0(2)$, and $112(6) \mathrm{kJ} \mathrm{mol}^{-1}$ and 16.0(9), respectively. It is shown, that in these complexes the MS1 isomers exhibit excellent thermal stability, trans-[RuNO$\left.\left(\mathrm{NH}_{3}\right)_{4} \mathrm{~F}\right]\left[\mathrm{PdCl}_{4}\right]$ exhibits the highest thermal stability known up to now. The spectroscopic analysis of ground and metastable states allows to underline two important features: i) the absorption of a counterion in the excitation range results in a decreased efficiency of light absorption of the nitrosyl complex cation and consequently leads to a decrease in metastable state population; ii) the interactions with the counterion can influence the position of absorption bands of MS1 and MS2, which requires to change the excitation wavelength for the achievement of the maximum metastable state population. Obtained results can be expanded and applied for other metastable systems, like complexes containing nitrite $\left(\mathrm{NO}_{2}^{-}\right)$or sulfoxide-like ( $\left.\mathrm{SO}\right)$ ligands.

\section{Introduction}

One types of the molecular machines consist of molecules capable of reversible changes between at least two states. In this regard, a variety of isomerization reactions can be employed to create the machine. The attractiveness of these reactions is caused by the two factors, the first is the difference in the absorption spectra of the given isomers rendering them optically distinguishable, and the second - by externally stimuli one isomer can be switched to another ${ }^{1}$. These molecular switches provide unique optical properties, essential for data storage and sensors technologies. One of the known class of molecules capable of reversible isomerization consists of nitrosyl metal complexes. Nitrosyl linkage isomerism is the ability of the nitrosyl ligand $\mathrm{NO}$ to be bound to the metal center in different ways through the nitrogen atom (M-NO, ground state - GS), the oxygen atom (M-ON, metastable state 1 MS1) or by the side bond type (M-(n $\left.\left.{ }^{2}-(\mathrm{NO})\right), \mathrm{MS} 2\right)^{2}$. An important feature of these isomers is that light irradiation of GS leads to the formation of MS1 through MS2 as intermediate state (GS $\rightarrow$ MS2 $\rightarrow$ MS1) 3,4 . This type of isomerism is characteristic for different metals, but the most prominent results and effects were observed in octahedral ruthenium complexes with general formula ${ }_{5}$ Ru-NO. 
Nitrosyl ruthenium complexes can be used as functional blocks for the assembly of materials combining photo-switchable and magnetic properties. Numerous attempts were made to create heterometallic materials based on ruthenium and iron nitrosyls with magnetic metal complexes. Analysis of photo-reversible properties in such materials reveal, that many of the obtained compounds lose photo-activity when the nitrosyl complex is embedded in a heterometallic complex. In work ${ }^{5}$ the absence of metastable states formation after light exposure of [Mn(3-MeOsalen) $\left.\left(\mathrm{H}_{2} \mathrm{O}\right)\right]_{2}\left[\mathrm{Fe}(\mathrm{CN})_{5} \mathrm{NO}\right]$ and $[\mathrm{Mn}(5-\mathrm{Brsalen})]_{2}\left[\mathrm{Fe}(\mathrm{CN})_{5} \mathrm{NO}\right]$ complexes containing $\left[\mathrm{Fe}(\mathrm{CN})_{5} \mathrm{NO}\right]^{2-}$ anion was explained by two reasons. The first is the very close contacts between the nitrosyl ligand and the nearest atoms of the counterion, the second is the nature of the metal ion ( $\left.\mathrm{Mn}^{\prime \prime \prime}\right)$. The same behavior was observed in other $\mathrm{Mn}^{\text {III }}$ heterometallic compounds ${ }^{6-8}$, however in $\left\{[\mathrm{Mn}(\mathrm{salpn})]_{2}\left[\mathrm{Fe}(\mathrm{CN})_{5} \mathrm{NO}\right]\right\}_{\mathrm{n}}$ and $\left\{\left[\mathrm{Mn}(\text { dapsc) }]\left[\mathrm{Fe}(\mathrm{CN})_{5} \mathrm{NO}\right] \cdot 0.5 \mathrm{CH}_{3} \mathrm{OH} \cdot 0.25 \mathrm{H}_{2} \mathrm{O}\right\}_{\mathrm{n}}\right.$ nitrosyls photo-isomerization was observed. In nickel complexes $\left[\mathrm{Ni}(\mathrm{en})_{2}\right]_{4}\left[\mathrm{Fe}(\mathrm{CN})_{5} \mathrm{NO}\right]_{2}\left[\mathrm{Fe}(\mathrm{CN})_{6}\right] \cdot 5 \mathrm{H}_{2} \mathrm{O}$ and $\left[\mathrm{Ni}(\mathrm{en})_{2}\right]\left[\mathrm{Fe}(\mathrm{CN})_{5} \mathrm{NO}\right] \cdot 3 \mathrm{H} 2 \mathrm{O}$ metastable states were found as well ${ }^{5}$. Ruthenium nitrosyl complexes $\left[\mathrm{RuNO}\left(\mathrm{NH}_{3}\right)_{5}\right]^{3+}$, trans- $\left[\mathrm{RuNO}\left(\mathrm{NH}_{3}\right)_{4}\left(\mathrm{H}_{2} \mathrm{O}\right)\right]^{3+}$, trans$\left[\mathrm{RuNO}(\mathrm{NH} 3)_{4} \mathrm{OH}\right]^{2+}$ and trans-[RuNO$\left.\left(\mathrm{en}_{2}\right)_{4} \mathrm{Cl}\right]^{2+}$ with a variety of metal anions were examined on metastable states formation ${ }^{9-15}$. It was shown, that the population of metastable states changes and depends on the anion. For example, for $\left[\mathrm{RuNO}\left(\mathrm{NH}_{3}\right)_{5}\right]^{3+}$ salts with $\left[\mathrm{Co}(\mathrm{CN})_{6}\right]^{3-},\left[\mathrm{ZrF}_{6}\right]^{2-},\left[\mathrm{Cr}(\mathrm{CN})_{6}\right]^{3-}$ and $\mathrm{Cl}^{-}$anions, MS1 population is 50, 39, 30 and 32, respectively. Since MS1 population is determined, amongst other factors, by the overlapping of absorption bands of GS, MS1 and MS2 at the irradiation wavelength, spectral analysis of all states is needed to fully understand the population behavior ${ }^{16}$. Hence, there are evidences that the nature of the counterion strongly affects the MS1 population, but these facts were not supported by experimental spectroscopic data, whereas it is essential for the design of photochromic materials.

Recently, we obtained trans- $\left[\mathrm{RuNO}\left(\mathrm{NH}_{3}\right)_{4} \mathrm{~F}\right] \mathrm{SiF}_{6}$ complex $\left(\left[\mathrm{RuNO}\left(\mathrm{NH}_{3}\right)_{4} \mathrm{~F}\right]^{2+}=\mathrm{A}^{2+}\right)$, which exhibited the highest thermal stability of MS1 and decent photochromic response ${ }^{17}$. MS1 and MS2 in the complex were investigated by spectroscopic (IR, UV-Vis) and X-Ray diffraction techniques (XRD) and it was shown, that MS1 can be generated by continuous-wave light source at room temperature (300 K). In addition to metastable states formation, this complex exhibits stable second harmonic emission upon femtosecond-pulsed irradiation. Since the trans-[RuNO$\left.\left(\mathrm{NH}_{3}\right)_{4} \mathrm{~F}\right]^{2+}$ core exhibits a variety of intriguing properties, it is of interest to understand how the counterion can influence the photochromic response and how we can improve known properties by the rational design of the complex. For this task, simple noble-metal-based anions $\left[\mathrm{PtCl}_{6}\right]^{2-},\left[\mathrm{PdCl}_{4}\right]^{2-}$ and $\left[\mathrm{PtCl}_{4}\right]^{2-}$ were chosen. As a reference the complex with perchlorate anion $\mathrm{ClO}_{4}{ }^{-}$was prepared.

Thus, in the current work we analyze synthesized salts of $\mathrm{A}^{2+}$ complex with $\left[\mathrm{PtCl}_{6}\right]^{2-},\left[\mathrm{PdCl}_{4}\right]^{2-},\left[\mathrm{PtCl}_{4}\right]^{2-}$ and $\mathrm{ClO}_{4}{ }^{-}$anions in order to investigate the influence of the counterion on the structure, spectroscopic and thermal properties of the metastable states. The double complex salts (DCS) $A\left[\mathrm{PtCl}_{6}\right], A\left[\mathrm{PdCl}_{4}\right]$ and $\mathrm{A}\left[\mathrm{PtCl}_{4}\right]$ as well as the $\mathrm{A}\left(\mathrm{ClO}_{4}\right)_{2}$ complex were characterized by single crystal X-Ray diffraction. All the complexes show MS1 formation after blue-light irradiation. $\mathrm{A}\left(\mathrm{ClO}_{4}\right)_{2}$ also shows $\mathrm{MS} 2$ formation after subsequent infrared irradiation, which was detected by IR, UV-Vis spectroscopy and differential scanning calorimetry (DSC). The dependence of MS1 population on the absorption properties of the GS, MS1 and MS2 was systematically studied based on UV-Vis data.

\section{Experimental}

\section{Synthesis of a "trans-[RuNO$\left.\left(\mathrm{NH}_{3}\right)_{4} \mathrm{~F}\right]\left(\mathrm{NO}_{3}\right)_{2}$ " precursor}


The complex was synthesized according to the method described earlier ${ }^{17}$. The salt trans[RuNO$\left.\left(\mathrm{NH}_{3}\right)_{4} \mathrm{OH}\right] \mathrm{Cl}_{2}$ was converted to the nitrate salt trans-[RuNO$\left.\left(\mathrm{NH}_{3}\right)_{4} \mathrm{OH}\right]\left(\mathrm{NO}_{3}\right)_{2}$ by the equimolar mixing of water solutions of trans- $\left[\mathrm{RuNO}\left(\mathrm{NH}_{3}\right)_{4} \mathrm{OH}\right] \mathrm{Cl}_{2}$ and $\mathrm{AgNO}_{3}$, in order to prevent chloride-ion coordination to ruthenium. Then the trans- $\left[\mathrm{RuNO}\left(\mathrm{NH}_{3}\right)_{4} \mathrm{OH}\right]\left(\mathrm{NO}_{3}\right)_{2}$ powder was washed on glass filter by the acetone and diethyl ether. The resulting complex was heated with concentrated HF (40\%) for $30 \mathrm{~h}$ at $363 \mathrm{~K}$ in a closed plastic beaker on an oil bath. Evaporation of the hydrofluoric acid has given a yellow residue with presumable formula «trans-[RuNO$\left.\left(\mathrm{NH}_{3}\right)_{4} \mathrm{~F}\right]\left(\mathrm{NO}_{3}\right)_{2}$ ». The final product was washed with diethyl ether.

\section{Synthesis of trans-[RuNO$\left.\left(\mathrm{NH}_{3}\right)_{4} \mathrm{~F}\right]\left[\mathrm{PtCl}{ }_{6}\right]$, trans-[RuNO$\left.\left(\mathrm{NH}_{3}\right)_{4} \mathrm{~F}\right]\left[\mathrm{PdCl} l_{4}\right]$ and trans- [RuNO(NH$\left.\left.)_{4}\right)_{4}\right]\left[\mathrm{PtCl}_{4}\right]$}

Equimolar water solutions of the parent complex «trans- $\left[\mathrm{RuNO}\left(\mathrm{NH}_{3}\right)_{4} \mathrm{~F}\right]\left(\mathrm{NO}_{3}\right)_{2}$ » and $\mathrm{K}_{2} \mathrm{PdCl}_{4}, \mathrm{~K}_{2} \mathrm{PtCl}_{4}$ or $\mathrm{Na}_{2} \mathrm{PtCl}_{6} \cdot 6 \mathrm{H}_{2} \mathrm{O}$ salt were mixed in plastic tube resulting in the formation of the corresponding double complex salt (DCS). The obtained DCSs were filtered on porous glass filter and washed with water, acetone and diethyl ether. The yield of obtained complexes is $~ 80 \%$. Single crystals of the complexes suitable for single-crystal X-ray diffraction (SCXRD) were obtained by slow diffusion of water solution of $\mathrm{Pd}$ or Pt parent salt into water solution of «trans-[RuNO$\left.\left(\mathrm{NH}_{3}\right)_{4} \mathrm{~F}\right]\left(\mathrm{NO}_{3}\right)_{2}$ » precursor in a plastic tube in a fridge. The powder XRD patterns of the bulk samples corresponds to the theoretical patterns calculated from the crystal structures determined by single-crystal XRD.

trans-[RuNO $\left.\left(\mathrm{NH}_{3}\right)_{4} \mathrm{~F}\right]\left[\mathrm{PtCl}_{6}\right]$ : IR bands at room temperature: 3260, $3161(\mathrm{U}(\mathrm{N}-\mathrm{H})) ; 1873(\mathrm{U}(\mathrm{N}-\mathrm{O}))$; 1625, 1559, 1344 and $1298(\delta(\mathrm{H}-\mathrm{N}-\mathrm{H})) ; 848\left(\rho\left(\mathrm{NH}_{3}\right)\right)$. Elemental analysis for $\mathrm{Ru}_{1} \mathrm{~N}_{5} \mathrm{O}_{1} \mathrm{H}_{12} \mathrm{~F}_{1} \mathrm{Pt}_{1} \mathrm{Cl}_{6}$, calculated/found (\%): H 1.9/2.1, N 11.2/10.7.

trans-[RuNO $\left.\left(\mathrm{NH}_{3}\right)_{4} \mathrm{~F}\right]\left[\mathrm{PdCl}_{4}\right]$ : IR bands at room temperature: 3266, $3180(\mathrm{U}(\mathrm{N}-\mathrm{H})) ; 1892$ and 1886 $(\mathrm{U}(\mathrm{N}-\mathrm{O})) ; 1631,1600,1343$ and $1327(\delta(\mathrm{H}-\mathrm{N}-\mathrm{H})) ; 841\left(\rho\left(\mathrm{NH}_{3}\right)\right)$. Elemental analysis for $\mathrm{Ru}_{1} \mathrm{~N}_{5} \mathrm{O}_{1} \mathrm{H}_{12} \mathrm{~F}_{1} \mathrm{Pd}_{1} \mathrm{Cl}_{4}$, calculated/found (\%): $\mathrm{H}$ 2.6/2.7, $\mathrm{N}$ 15.0/14.7.

trans-[RuNO$\left.\left(\mathrm{NH}_{3}\right)_{4} \mathrm{~F}\right]\left[\mathrm{PtCl}_{4}\right]$ : IR bands at room temperature: 3274, $3191(\mathrm{U}(\mathrm{N}-\mathrm{H})) ; 1901$ and 1891 $(\mathrm{U}(\mathrm{N}-\mathrm{O})) ; 1633,1344$ and $1324(\delta(\mathrm{H}-\mathrm{N}-\mathrm{H})) ; 843$ and $744\left(\rho\left(\mathrm{NH}_{3}\right)\right)$. Elemental analysis for $\mathrm{Ru}_{1} \mathrm{~N}_{5} \mathrm{O}_{1} \mathrm{H}_{12} \mathrm{~F}_{1} \mathrm{Pt}_{1} \mathrm{Cl}_{4}$, calculated/found (\%): $\mathrm{H}$ 2.2/1.9, $\mathrm{N}$ 12.6/12.0.

\section{Synthesis of trans-[RuNO$\left.\left(\mathrm{NH}_{3}\right)_{4} \mathrm{~F}\right]\left(\mathrm{ClO}_{4}\right)_{2}$}

The $10 \%$ solution of $\mathrm{HClO}_{4}$ was added to the saturated water solution of "trans[RuNO $\left.\left(\mathrm{NH}_{3}\right)_{4} \mathrm{~F}\right]\left(\mathrm{NO}_{3}\right)_{2}$ " in a plastic tube. Yellow powder was readily formed and then washed with diethyl ether and acetone on a glass filter. The yield of the complex is $\sim 80 \%$. Crystals suitable for singlecrystal XRD were obtained by the slow evaporation of the hot saturated water solution of the trans$\left[\mathrm{RuNO}\left(\mathrm{NH}_{3}\right)_{4} \mathrm{~F}\right]\left(\mathrm{ClO}_{4}\right)_{2}$. The powder XRD pattern of the bulk sample corresponds to the theoretical pattern calculated from the crystal structure determined by single-crystal XRD. IR bands at room temperature: 3262, $3146(\mathrm{U}(\mathrm{N}-\mathrm{H})) ; 1874(\mathrm{U}(\mathrm{NO})) ; 1628,1565,1325$ and $1299(\delta(\mathrm{H}-\mathrm{N}-\mathrm{H})) ; 1145,1122$, 1109 and $1089(\mathrm{U}(\mathrm{Cl}-\mathrm{O})) ; 844\left(\rho\left(\mathrm{NH}_{3}\right)\right)$. Elemental analysis for $\mathrm{Ru}_{1} \mathrm{~N}_{5} \mathrm{O}_{9} \mathrm{H}_{12} \mathrm{~F}_{1} \mathrm{Cl}_{2}$, calculated/found $(\%): \mathrm{H}$ 2.9/3.1, N 16.8/17.3.

\section{Single-crystal X-Ray diffraction}

Single crystal X-ray diffraction data were collected on a Bruker Apex Duo diffractometer with CCDs using graphite-monochromated MoK $\alpha$ radiation $\left(\lambda=0.71073 \AA\right.$ ) via $0.5^{\circ} \omega$ - and $\phi$-scan techniques. Reduction of the experimental data was performed using the APEX2 suite. The structures were solved 
by SHELXT and refined by the full-matrix least-squares technique SHELXL ${ }^{18}$ assisted with the Olex2 GUI ${ }^{19}$. The atomic displacement parameters of the ordered non-H atoms were refined using an anisotropic approximation. The hydrogen atoms of the amine ligands were located geometrically and refined using the riding model. Crystallographic characteristics, experimental data, and the structure refinements are listed in Table S1. The structures of trans-[RuNO $\left.\left(\mathrm{NH}_{3}\right)_{4} \mathrm{~F}\right]\left[\mathrm{PtCl} l_{6}\right]$, trans- $\left[\mathrm{RuNO}\left(\mathrm{NH}_{3}\right)_{4} \mathrm{~F}\right]\left[\mathrm{PdCl}{ }_{4}\right]$, trans$\left[\mathrm{RuNO}\left(\mathrm{NH}_{3}\right)_{4} \mathrm{~F}\right]\left[\mathrm{PtCl}_{4}\right]$ and trans-[RuNO$\left.\left(\mathrm{NH}_{3}\right)_{4} \mathrm{~F}\right]\left(\mathrm{ClO}_{4}\right)_{2}$ have been deposited with the CCDC with refcodes 2016494 - 2016497 respectively.

\section{IR and UV-Vis spectroscopy}

IR spectroscopy measurements with irradiation were performed using a Nicolet 5700 FT-IR spectrometer with a resolution of $2 \mathrm{~cm}^{-1}$ in the range $400-4000 \mathrm{~cm}^{-1}$. The sample was ground, mixed with $\mathrm{KBr}$ and pressed into standard pellets. The $\mathrm{KBr}$ pellets were bonded by silver paste for fixing onto the cold finger of a closed-cycle cryostat (Oxford Optistat V01). The irradiation procedures were performed by LEDs (Light Emitting Diodes) through $\mathrm{KBr}$ windows perpendicular to the samples with light of different wavelengths in the range $300-940 \mathrm{~nm}$ and $10-400 \mathrm{~mW}$ optical power (Thorlabs $L$ and LP series). The cryostat allows control of the temperature in the range 9-320 K. UV-Vis spectra were recorded using transparent $\mathrm{KBr}$ pellets with the complex by a Varian CARY 4000 spectrometer. Transparent pellets were prepared and irradiated as for the IR measurements. Low-temperature measurements were performed using the same cryostat as for the IR measurements, except that the $\mathrm{KBr}$ windows were exchanged for standard borosilicate glass windows. The baseline was measured using the same diaphragm with a $\mathrm{KBr}$ pellet, which can be mounted on the cryostat sample holder.

\section{Differential scanning calorimetry}

Differential scanning calorimeter NETZSCH DSC 204 F1 Phoenix was used to study kinetics and thermal effects accompanying the reverse MS1- GS process. DSC measurements of 1-3 mg powdered samples were performed in open aluminum crucibles by the heat flow measurement method at different heating rates $\left(9-12 \mathrm{~K} \mathrm{~min}^{-1}\right)$ in $25 \mathrm{ml} / \mathrm{min}$ Ar flow. In order to increase the accuracy, measurements were carried out without a supply of gas/liquid nitrogen into the measurement cell during the experiment. The sensitivity calibration of the sample carrier sensors and temperature scale graduation were performed by melting and crystal-to-crystal transition measurements of standard samples $\left(\mathrm{C}_{6} \mathrm{H}_{12}, \mathrm{Hg}, \mathrm{KNO}_{3}, \mathrm{In}\right)$. For MS1 generation, irradiation of GS was performed at $80 \mathrm{~K}$ for $15 \mathrm{~min}$, using LED light at $405 \mathrm{~nm}$ and with a light intensity of $200 \mathrm{~mW}$. Processing of the experimental data was performed with Netzsch Proteus Analysis software.

\section{Elemental analysis}

The elemental content of the complexes ( $\mathrm{H}$ and $\mathrm{N}$ atoms) was determined using a standard combustion Vario Microcube analyzer.

\section{Hirshfeld surface analysis}

The Hirshfeld surfaces were calculated using Crystal Explorer 20,21. This program allows the normalized contact distance $d_{\text {norm }}$ to be mapped onto the generated Hirshfeld surface. It is customary to map $d_{\text {norm }}$ using a red-white-blue scheme, where red denotes close intermolecular contacts (negative $d_{\text {norm }}$ ), blue denotes longer contacts (positive $d_{\text {norm }}$ ) and white denotes intermolecular contacts equal to the van der Waals radii of atoms in contact $\left(d_{\text {norm }}=0\right)$. It is possible to obtain twodimensional plots (fingerprint plots) from the surfaces mapped with $d_{\text {norm }}$ values. Derived from the Hirshfeld surface, these 2D-fingerprint plots provide a visual summary of the frequency of each 
combination of $d_{e}$ (radius of external atom) and $d_{i}$ (radius of internal atom) across the surface of a molecule, so they not only indicate which intermolecular interactions are present, but also the relative area of the surface corresponding to each kind of interaction. Points on the plot with no contribution on the surface are left uncoloured, and points with a contribution to the surface are coloured blue for a small contribution through green to red for points with the greatest contribution.

\section{Results and discussion}

\section{Structure analysis}

The crystal structures of the complexes are presented by the ruthenium octahedra trans$\left[\mathrm{RuNO}\left(\mathrm{NH}_{3}\right)_{4} \mathrm{~F}\right]^{2+}=\mathrm{A}$ and corresponding anion: $\left[\mathrm{PtCl}_{6}\right]^{2-}$ (octahedron), $\left[\mathrm{PdCl}_{4}\right]^{2-}$ (square), $\left[\mathrm{PdCl}_{4}\right]^{2-}$ (square), or $\mathrm{ClO}_{4}^{2-}$ (tetrahedron). In the structure of $\mathrm{A}\left(\mathrm{ClO}_{4}\right)_{2}$ there are two non-equivalent trans[RuNO$\left.\left(\mathrm{NH}_{3}\right)_{4} \mathrm{~F}\right]\left(\mathrm{ClO}_{4}\right)_{2}$ parts with slightly different bond lengths (see Fig. 1 and Table 1). Amine ligands of the ruthenium cation are located in the same plane, whereas nitrosyl and fluoride ligands are in trans-position to each other. The $\mathrm{N}-\mathrm{O}$ bond distances of the nitrosyl ligand and Ru-NO bond lengths do not change significantly when the anion change, these bond distances are typical for ruthenium nitrosyl complexes with almost linear $\mathrm{Ru}^{\prime \prime}-\mathrm{NO}^{+}$core ${ }^{22}$. The bond distances for trans-[RuNO$\left.\left(\mathrm{NH}_{3}\right)_{4} \mathrm{~F}\right]^{2+}$ are listed in Table 1, the bond distances of the anions are shown in Tables S2 and S3. The ruthenium octahedron is slightly distorted - the angles $\mathrm{Ru}-\mathrm{N}-\mathrm{O}$ and $\mathrm{F}-\mathrm{Ru}-\mathrm{N}(\mathrm{NO})$ are close to $180^{\circ}$ and vary in the range 174.9(18)-179.3(1) ${ }^{\circ}$, whereas F-Ru- $\mathrm{N}\left(\mathrm{NH}_{3}\right)$ angles are close to $90^{\circ}$ (vary in the range 84.6(5)-86.1(5) ${ }^{\circ}$ ). The Ru-F and $\mathrm{Ru}-\mathrm{NH}_{3}$ bond lengths are influenced by the involvement of fluoride and amine ligands in the formation of hydrogen bonds, which is discussed below.

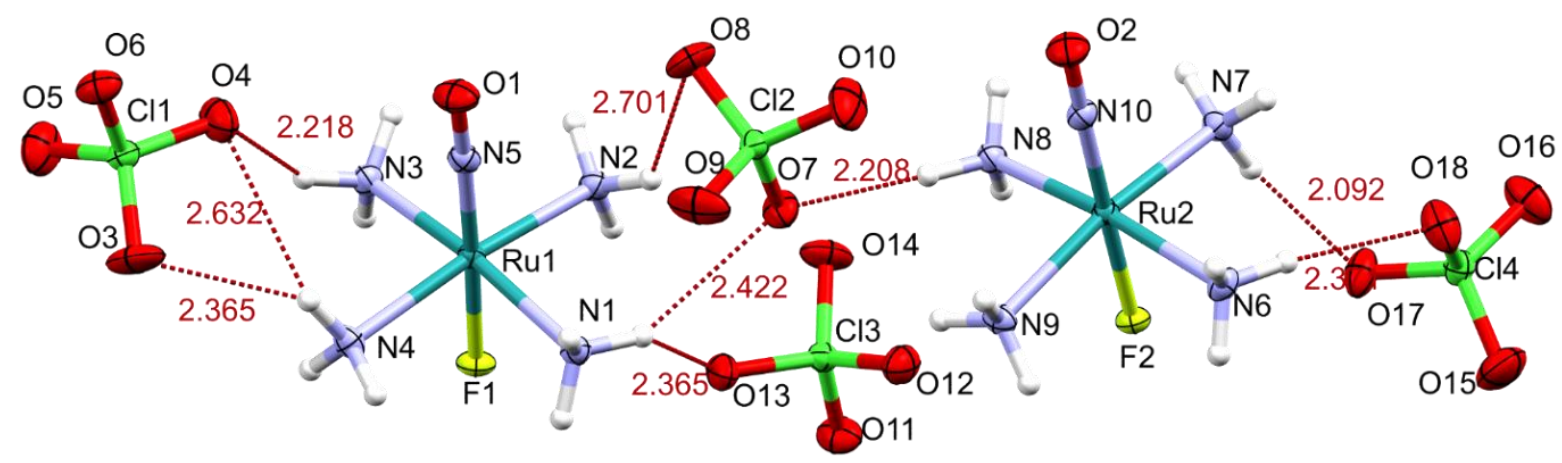

Fig. 1. The fragment of $A\left(\mathrm{ClO}_{4}\right)_{2}$ structure with chosen depicted hydrogen bonds. Thermal ellipsoids are given at the $50 \%$ probability level.

Table 1. Selected bond lengths $(\AA)$ and angles $\left(^{\circ}\right)$ in trans- $\left[\mathrm{RuNO}\left(\mathrm{NH}_{3}\right)_{4} \mathrm{~F}\right]^{2+}$ for the obtained complexes with different anions.

\begin{tabular}{|c|c|c|c|c|}
\hline \multirow{2}{*}{ Distance/angle } & \multicolumn{4}{|c|}{ The complex } \\
\cline { 2 - 5 } & $\mathrm{A}\left[\mathrm{PtCl}_{4}\right]$ & $\mathrm{A}\left[\mathrm{PdCl}_{4}\right]$ & $\mathrm{A}\left[\mathrm{PtCl}_{6}\right]$ & $\mathrm{A}\left(\mathrm{ClO}_{4}\right)_{2}{ }^{*}$ \\
\hline N5-O1 & $1.150(20)$ & $1.149(5)$ & $1.153(7)$ & $1.138(4) ; 1.141(4)$ \\
\hline Ru1-N5 & $1.738(19)$ & $1.728(5)$ & $1.728(5)$ & $1.740(3) ; 1.736(3)$ \\
\hline Ru1-N1 & $2.084(13)$ & $2.089(3)$ & $2.099(5)$ & $2.097(3) ; 2.100(2)$ \\
\hline Ru1-N2 & $2.084(13)$ & $2.089(3)$ & $2.097(5)$ & $2.103(3) ; 2.104(3)$ \\
\hline Ru1-N3 & $2.110(12)$ & $2.101(3)$ & $2.105(5)$ & $2.105(2) ; 2.102(3)$ \\
\hline Ru1-N4 & $2.110(12)$ & $2.101(3)$ & $2.107(5)$ & $2.091(3) ; 2.102(3)$ \\
\hline Ru1-F1 & $1.963(12)$ & $1.938(3)$ & $1.917(4)$ & $1.927(2) ; 1.937(2)$ \\
\hline
\end{tabular}




\begin{tabular}{|c|c|c|c|c|}
\hline Ru1-N5-O1 & $174.9(18)$ & $175.4(4)$ & $177.4(5)$ & $178.1(2) ; 178.9(2)$ \\
\hline F1-Ru1-N5 & $177.8(7)$ & $177.9(2)$ & $178.7(2)$ & $178.4(1) ; 179.3(1)$ \\
\hline N1-Ru1-F1 & $84.6(5)$ & $85.3(1)$ & $85.4(2)$ & $84.9(1) ; 85.1(1)$ \\
\hline N2-Ru1-F1 & $84.6(5)$ & $85.3(1)$ & $85.5(2)$ & $86.1(1) ; 85.2(1)$ \\
\hline N3-Ru1-F1 & $86.1(5)$ & $85.8(1)$ & $85.7(2)$ & $85.1(1) ; 86.1(1)$ \\
\hline N4-Ru1-F1 & $86.1(5)$ & $85.8(1)$ & $85.7(2)$ & $84.6(1) ; 84.8(1)$ \\
\hline \multicolumn{5}{|c|}{$\begin{array}{l}\text { *The first value corresponds to the Ru1 part, the second - to the Ru2. In case } \\
\text { of Ru2 part, distances Ru1-N1...Ru1-N5 corresponds to the Ru2-N6...Ru2-N10 } \\
\text { bonds, Ru1-F1 corresponds to the Ru2-F2 and O1 to the O2 atom. }\end{array}$} \\
\hline
\end{tabular}

The double complex salts (DCSs) crystallize in non-centrosymmetric space groups ( $P 2_{1} 2_{1} 2_{1}$ and $\mathrm{Cmc2}_{1}$ for $\mathrm{A}\left[\mathrm{PtCl}_{6}\right]$ and $\mathrm{A}\left[\mathrm{PtCl}_{4}\right], \mathrm{A}\left[\mathrm{PdCl}_{4}\right]$ respectively), which could provide potential second order non-linear optical response after pulsed light irradiation of the complexes ${ }^{17,23}$. Since the cation and anion fragments are relatively symmetric in all cases, the packing in a non-centrosymmetric crystal structure is determined by intermolecular interactions, the strongest ones are formed by the hydrogen bonds (Table S4). Selected distances for short contacts in the $A\left[\mathrm{PtCl}_{6}\right]$ complex are shown in Fig. 2 . The $\mathrm{H} \cdots \mathrm{Cl}$ distances in $\mathrm{N}-\mathrm{H} \cdots \mathrm{Cl}$ vary in the range 2.433-2.927 $\AA$ (angles in the range 82.93-176.36 $)$, the average hydrogen bond length and angle is $2.735 \AA$ and $138.89^{\circ}$, respectively. Another hydrogen bond is found between fluoride and the hydrogen atom of the amine ligand $\mathrm{N} 4-\mathrm{H} \cdots \mathrm{F} 1$ with a distance of $2.399 \AA$ and an angle of $114.61^{\circ}$. A relatively short contact is found also between oxygen atom of nitrosyl ligand and chloride ligand, the $01 \cdots \mathrm{Cl} 5$ distance is $3.123 \AA$, and the angle N5-O1-Cl5 is $145.24^{\circ}$. Similar halogen-NO contacts were observed earlier in the complex trans-[RuNO$\left.\left(\mathrm{NH}_{3}\right)_{4} \mathrm{~F}\right] \mathrm{SiF}_{6}{ }^{17}$.

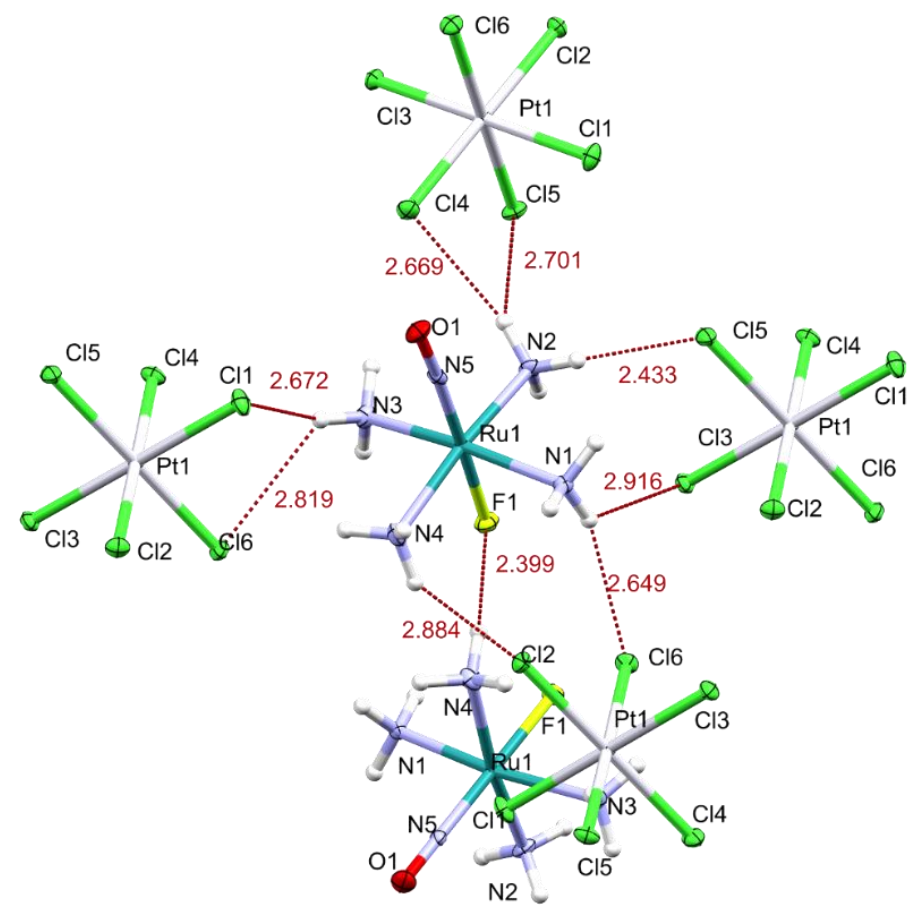

Fig. 2. The fragment of $A\left[\mathrm{PtCl}_{6}\right]$ structure with chosen depicted hydrogen bonds. Thermal ellipsoids are given at the $50 \%$ probability level.

For a more quantitative estimation of the impact of a certain atom to the entire intermolecular interactions, Hirshfeld surfaces were analyzed ${ }^{20,21}$. The two-dimensional fingerprint plot of Hirshfeld surfaces of the trans-[RuNO$\left.\left(\mathrm{NH}_{3}\right)_{4} \mathrm{~F}\right]^{2+}$ and $\left[\mathrm{PtCl}_{6}\right]^{2-}$ ions are shown in Fig. 3 and $\mathrm{S} 1$, respectively. 
According to the two-dimensional fingerprint plots of $\left[\mathrm{PtCl}_{6}\right]^{2-}$, the biggest contribution is made by the $\mathrm{Cl} \cdots \mathrm{H}$ interactions (74.9\%), i.e. by hydrogen bonds (see Fig. 2 for illustration). Concerning the ruthenium octahedron, the major part of the intermolecular interactions is formed by the hydrogen atoms as well (76.0\%), mainly by means of the $\mathrm{N}-\mathrm{H} \cdots \mathrm{Cl}$ hydrogen bonds $(59.2 \%$ out of $76.0 \%)$. The abundance of $\mathrm{H} \cdots \mathrm{Cl}$ contacts within van der Waals radii is relatively very high (red areas on the panel $b$ of the Fig 3 ) with respect to other contacts. The rest of intermolecular interactions are formed by the oxygen (13.9\%) and fluoride atoms ( $7.4 \%)$ by means of halogen and hydrogen bonds, respectively.

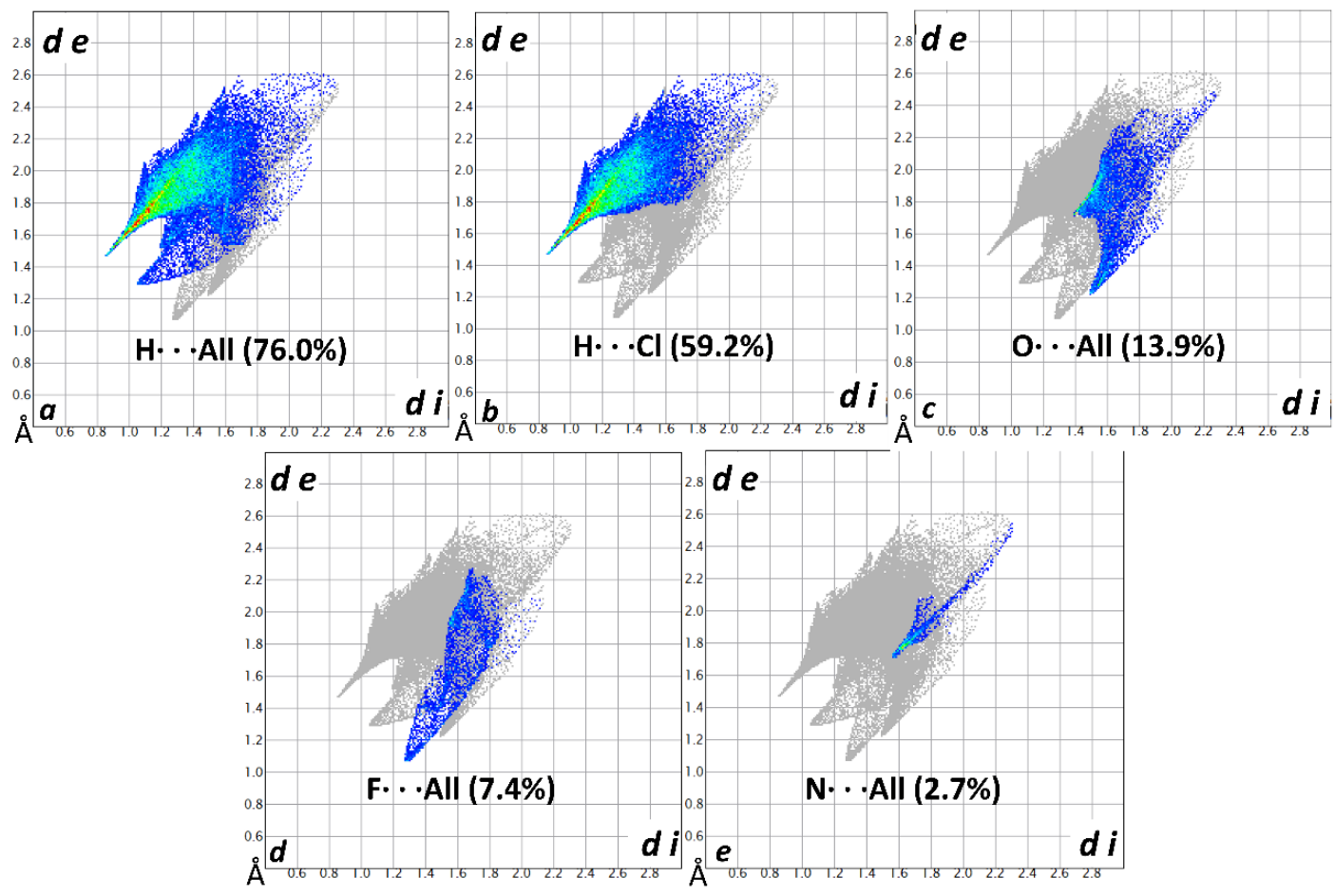

Fig. 3. Two-dimensional fingerprint plots of Hirshfeld surface of the trans- $\left[\mathrm{RuNO}\left(\mathrm{NH}_{3}\right)_{4} \mathrm{~F}\right]^{2+}$ in $\mathrm{A}\left[\mathrm{PtCl}_{6}\right]$. Panels $a, c, d$ and $e$ represents all found contacts of hydrogen, oxygen, fluoride and nitrogen atoms respectively, panel $b$ shows $\mathrm{H} \cdots \mathrm{Cl}$ intermolecular interactions.

The complexes $\mathrm{A}\left[\mathrm{PtCl}_{4}\right]$ and $\mathrm{A}\left[\mathrm{PdCl}_{4}\right]$ are isostructural (space group $\mathrm{Cmc} 2_{1}$ ). In both complexes the intermolecular interactions are mainly due to hydrogen bonds similar to the $A\left[\mathrm{PtCl}_{6}\right]$ compound (see Fig. 4). In the case of $A\left[\mathrm{PdCl}_{4}\right]$ the $\mathrm{H} \cdots \mathrm{Cl}$ distances in $\mathrm{N}-\mathrm{H} \cdots \mathrm{Cl}$ vary in the range 2.458-2.912 $\AA$ (angles in the range $111.97-171.59^{\circ}$ ), the average hydrogen bond length and angle is $2.702 \AA$ and $144.22^{\circ}$ respectively. For $A\left[\mathrm{PtCl}_{4}\right]$ the average hydrogen bond distance is almost the same $-2.656 \AA$ with average $\mathrm{N}-\mathrm{H} \cdots \mathrm{Cl}$ angle $146.50^{\circ}$. Besides of $\mathrm{N}-\mathrm{H} \cdots \mathrm{Cl}$ hydrogen bonds, $\mathrm{N}-\mathrm{H} \cdots \mathrm{F}$ interactions are found. These hydrogen bonds with distances (angles) of $2.046 \AA\left(149.12^{\circ}\right)$ and $2.148 \AA\left(142.20^{\circ}\right)$ for $A\left[\mathrm{PdCl}_{4}\right]$ and $A\left[\mathrm{PtCl}_{4}\right]$ respectively, are stronger with respect to those in $A\left[\mathrm{PtCl}_{6}\right]\left(2.399 \AA, 114.61^{\circ}\right)$ and equal. Such close contacts induce an elongation of the Ru- $F$ bond lengths, which are 1.938(3) and 1.963(12) $\AA$ for $\mathrm{A}\left[\mathrm{PdCl}_{4}\right]$ and $\mathrm{A}\left[\mathrm{PtCl}_{4}\right]$ respectively, compared to $1.917(4) \AA$ in case of $\mathrm{A}\left[\mathrm{PtCl}_{6}\right]$. 

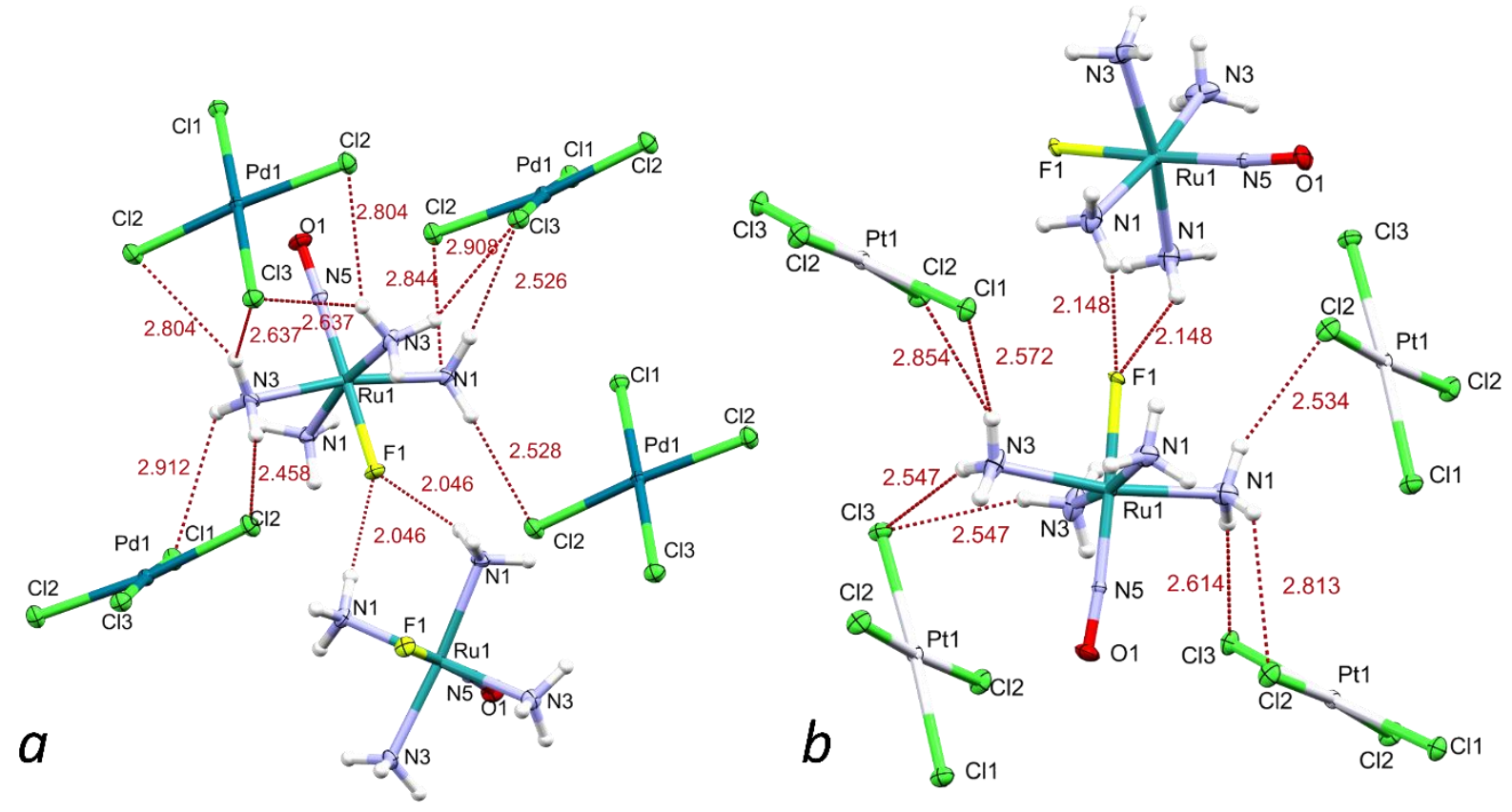

Fig. 4. The fragments of $\mathrm{A}\left[\mathrm{PdCl}_{4}\right](a)$ and $\mathrm{A}\left[\mathrm{PtCl}_{4}\right](b)$ structures with chosen depicted hydrogen bonds. Thermal ellipsoids are given at the $50 \%$ probability level. The N1 and N2 as well as the N3 and $\mathrm{N} 4$ atoms are symmetry equivalent and shown as $\mathrm{N} 1 / \mathrm{N} 3 . \mathrm{Cl} 2$ and $\mathrm{C} 4$ atoms of the $\mathrm{Pd}$ and Pt anions are symmetry equivalent and shown as $\mathrm{Cl} 2$.

The analysis of the two-dimensional fingerprint plots of $A\left[\mathrm{PdCl}_{4}\right]$ and $A\left[\mathrm{PtCl}_{4}\right]$ Hirshfeld surfaces reveals similar distribution of intermolecular interactions in these complexes (see Fig. 5, S2 and S3). About $\sim 80 \%$ of the Hirshfeld surfaces of the anionic parts $\left(\left[\mathrm{PdCl}_{4}\right]^{2-}\right.$ and $\left.\left[\mathrm{PtCl}_{4}\right]^{2-}\right)$ are represented by the $\mathrm{H} \cdots \mathrm{Cl}$ contacts, i.e. by the $\mathrm{N}-\mathrm{H} \cdots \mathrm{Cl}$ hydrogen bonds. Less than $8 \%$ of the surfaces are formed by the $\mathrm{Pt} / \mathrm{Pd}$ atoms by means of weak $\mathrm{Pd} \cdots \mathrm{Cl} / \mathrm{Pd} \cdots \mathrm{Cl}$ and $\mathrm{Pd} \cdots \mathrm{O} / \mathrm{Pd} \cdots \mathrm{O}$ contacts. Intermolecular interactions of the cationic parts (trans-[RuNO$\left.\left(\mathrm{NH}_{3}\right)_{4} \mathrm{~F}\right]^{2+}$ ) of both complexes are presented by contacts of hydrogen atoms ( $~ 80 \%$ of Hirshfeld surfaces), the strongest are made by the hydrogen bonds $\mathrm{N}-\mathrm{H} \cdots \mathrm{Cl}(\sim 50 \%)$. Other interactions are formed by the fluoride ligands ( $\sim \%)$ and oxygen atoms ( $\sim 14 \%)$ by the hydrogen bonds $\mathrm{N}-\mathrm{H} \cdots \mathrm{F}$ and weak $\mathrm{O} \cdots \mathrm{Cl}$ interactions, respectively. 


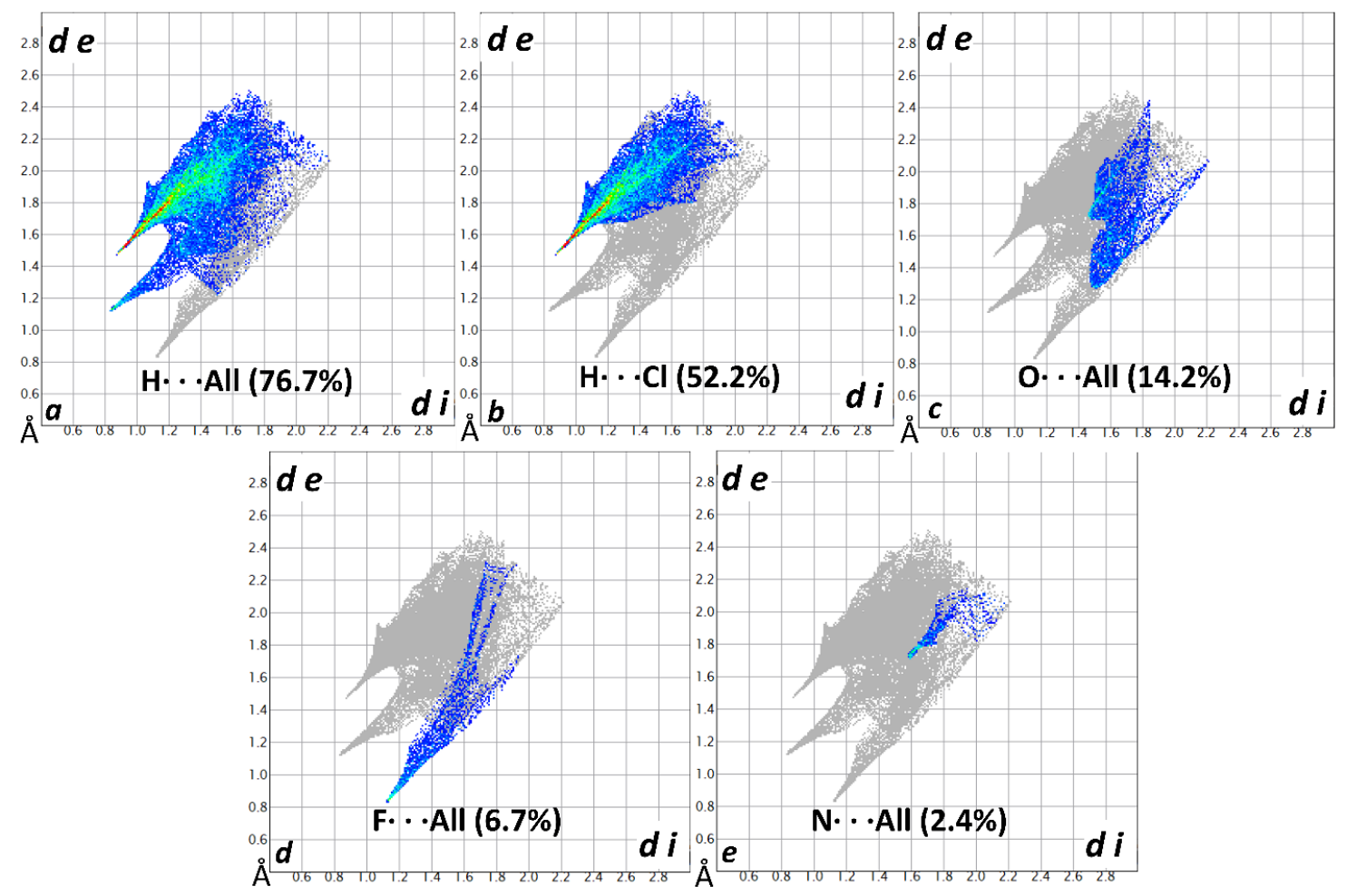

Fig. 5. The two-dimensional fingerprint plots of Hirshfeld surface of the trans- $\left[\mathrm{RuNO}\left(\mathrm{NH}_{3}\right)_{4} \mathrm{~F}\right]^{2+}$ in $\mathrm{A}\left[\mathrm{PdCl}_{4}\right]$. Panels $a, c, d$ and $e$ represents all found contacts of hydrogen, oxygen, fluoride and nitrogen atoms respectively, panel $b$ shows $\mathrm{H} \cdots \mathrm{Cl}$ intermolecular interactions.

Similar contribution of hydrogen bonds to the entire Hirshfeld surface of the trans-[RuNO$\left.\left(\mathrm{NH}_{3}\right)_{4} \mathrm{~F}\right]^{2+}$ cation $\left(66.9 \%\right.$ of the surface is formed by the $\mathrm{N}-\mathrm{H} \cdots \mathrm{O}$ contacts) is observed in the $\mathrm{A}\left(\mathrm{ClO}_{4}\right)_{2}$ complex (See Fig. 6). The average $\mathrm{H} \cdots \mathrm{O}$ distance of the $\mathrm{N}-\mathrm{H} \cdots \mathrm{O}$ hydrogen bonds is $2.417 \AA$ with average angle $136.6^{\circ}$. The hydrogen $\mathrm{N}-\mathrm{H} \cdots \mathrm{F}$ bonds noticeably influence the bond distances of the ruthenium octahedra. $\mathrm{A}$ longer Ru-F bond length (Ru2-F2 $=1.937(2) \AA$ ) is found for Ru2 octahedron, where the F2 ligand forms two hydrogen bonds $\left(\mathrm{N} 6-\mathrm{H} \cdots \mathrm{F} 2=2.160 \AA\left(156.0^{\circ}\right)\right.$ and $\left.\mathrm{N} 9-\mathrm{H} \cdots \mathrm{F} 2=2.128 \AA\left(159.2^{\circ}\right)\right)$, versus Ru1 octahedron, for which the Ru1-F1 bond distance equals $1.927(2) \AA$ with one $\mathrm{N}-\mathrm{H} \cdots \mathrm{F}$ hydrogen bond $\left(\mathrm{N} 1-\mathrm{H} \cdots \mathrm{F} 1=1.992 \AA\left(176.6^{\circ}\right)\right)$. The contribution of oxygen and fluoride atoms to the total Hirshfeld surface is 16.7 and $7.1 \%$ respectively, which is similar to the DCSs discussed above. 


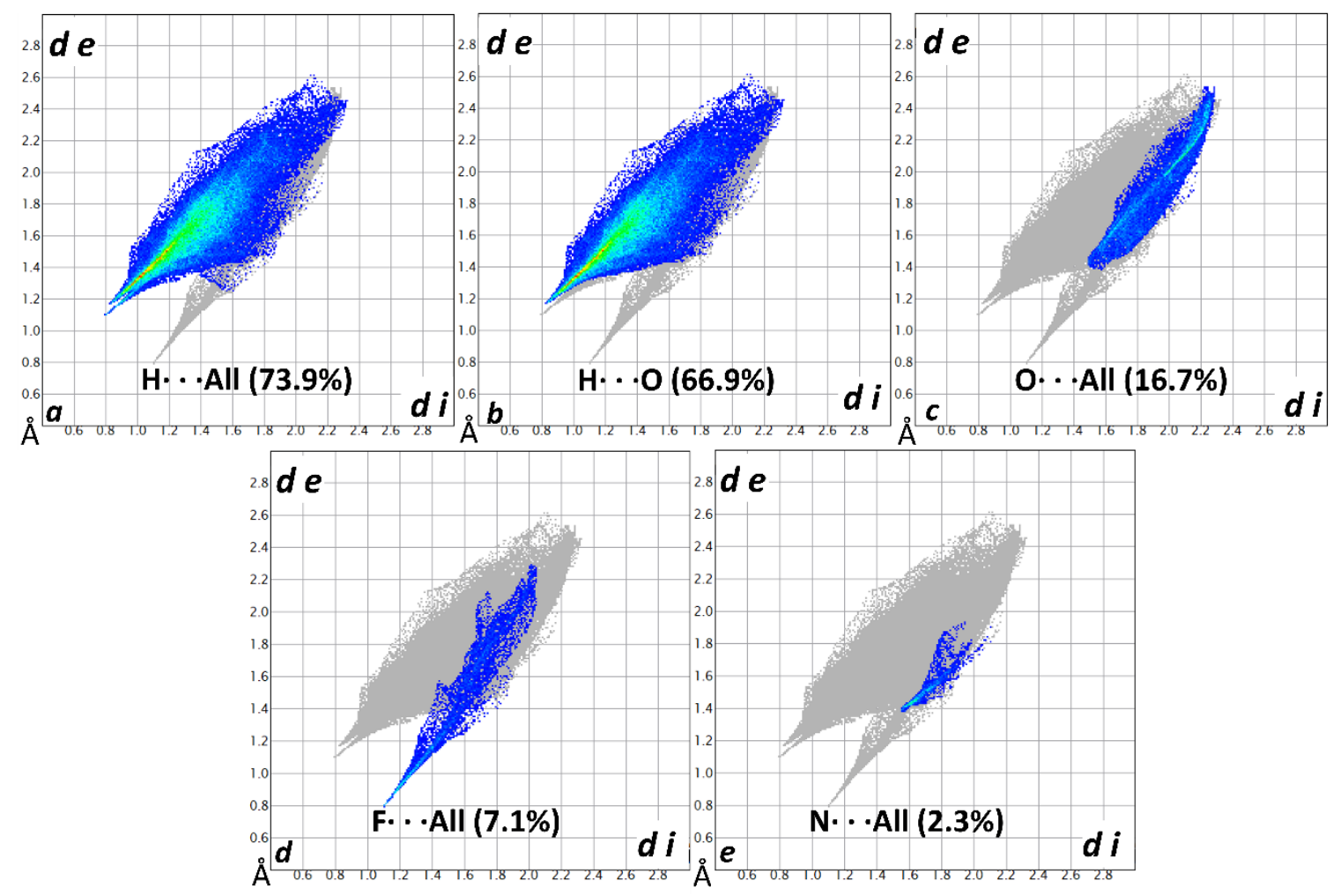

Fig. 6. The two-dimensional fingerprint plots of Hirshfeld surface of the trans- $\left[\mathrm{RuNO}\left(\mathrm{NH}_{3}\right)_{4} \mathrm{~F}\right]^{2+}$ in $\mathrm{A}\left(\mathrm{ClO}_{4}\right)_{2}$. Panels $a, c, d$ and $e$ represents all found contacts of hydrogen, oxygen, fluoride and nitrogen atoms respectively, panel $b$ shows $\mathrm{H} \cdots \mathrm{O}$ intermolecular interactions.

All in all, regardless of the anion, trans- $\left[\mathrm{RuNO}\left(\mathrm{NH}_{3}\right)_{4} \mathrm{~F}\right]^{2+}$ forms intermolecular interactions mostly by means of $\mathrm{N}-\mathrm{H} \cdots X$ hydrogen bonds $\left(\mathrm{X}=\mathrm{Cl}, \mathrm{F}^{17}\right.$ or $\left.\mathrm{O}\right)$. The contribution of these interactions to the total Hirshfeld surface is $\sim 70 \%$ and only slightly varies with the anion. The remainder of the total Hirshfeld surface is formed by the oxygen atoms contribution, but it does not exceed of $20 \%$ of the total surface. However, even though from this global perspective obtained from Hirshfeld surface analysis, the involvement of a certain atom of ruthenium center to the intermolecular interactions does not vary much from one anion to another, the space group symmetry of the structure is changed: while DCSs crystallize in acentric space groups, $\mathrm{A}\left(\mathrm{ClO}_{4}\right)_{2}$ exhibits a centrosymmetric structure. Since in all known cases anionic parts of the complexes have higher symmetry with respect to the trans$\left[\mathrm{RuNO}\left(\mathrm{NH}_{3}\right)_{4} \mathrm{~F}\right]^{2+}$ octahedron, apparently non-centrosymmetric structures rise from the ruthenium part and the specific intermolecular contacts (see Figsure 1,2,4). Commonly, an inclusion of asymmetric blocks or a presence of stronger hydrogen bonds in a structure can lead to the enhancement of the probability of the formation of a non-centrosymmetric structure ${ }^{24-27}$. Nevertheless, since in case of $\mathrm{SiF}_{6}{ }^{2-17},\left[\mathrm{PtCl}_{6}\right]^{2-},\left[\mathrm{PdCl}_{4}\right]^{2-}$ and $\left[\mathrm{PtCl}_{4}\right]^{2-}$ non-centrosymmetric structures were obtained, we can assume, that $\mathrm{N}-\mathrm{H} \cdots$ Halogen bonds are more favorable compared with $\mathrm{N}-\mathrm{H} \cdots \mathrm{O}$ bonds for the formation of asymmetric structures with trans-[RuNO$\left.\left(\mathrm{NH}_{3}\right)_{4} \mathrm{~F}\right]^{2+}$ cation.

\section{Photo-isomerization of nitrosyl ligand: IR-spectroscopy}

According to IR-spectroscopy at $10 \mathrm{~K}$, all obtained complexes exhibit $\mathrm{U}(\mathrm{N}-\mathrm{O})$ bands in the range of $1874-1910 \mathrm{~cm}^{-1}$, depending on anion (see Table 2), as well as bands related to ammine vibrations at $\approx 3200,1600,1300$ and $850 \mathrm{~cm}^{-1}$ (see Experimental part). Further characteristic bands of the complexes are found in the range $650-500 \mathrm{~cm}^{-1}$ related to the $u(\mathrm{Ru}-\mathrm{NO}) / \delta(\mathrm{Ru}-\mathrm{N}-\mathrm{O})$ vibrations (see Table 2). Unambiguous assignment of these bands to either $u(R u-N O)$ or $\delta(R u-N-O)$ modes is known to be 
difficult due to the uncertain sequence of the bands ${ }^{14,28-31}$. The band at $484-488 \mathrm{~cm}^{-1}$ (depending on the anion) is assigned to $\mathrm{U}(\mathrm{Ru}-\mathrm{F})$ stretching vibration. The complex with $\mathrm{ClO}_{4}{ }^{-}$anion shows an additional band at $1123 \mathrm{~cm}^{-1}((\mathrm{U}(\mathrm{Cl}-\mathrm{O})) \text {, broad })^{32}$. The presence of $\delta(\mathrm{Cl}-\mathrm{O})$ bands in $\mathrm{A}\left(\mathrm{ClO}_{4}\right)_{2}$ in $620-640 \mathrm{~cm}^{-1}$ range further obstruct the unambiguous assignment of $u(R u-N O) / \delta(R u-N-O)$ bands.

Table 2. Absorption bands of the complexes in infrared spectral range at $10 \mathrm{~K}$.

\begin{tabular}{|c|c|c|c|c|c|c|}
\hline \multirow{2}{*}{ Complex/Band } & \multicolumn{2}{|l|}{$\mathrm{u}(\mathrm{N}-\mathrm{O}), \mathrm{cm}^{-1}$} & \multicolumn{2}{|c|}{$\mathrm{u}(\mathrm{Ru}-\mathrm{NO}) / \delta(\mathrm{Ru}-\mathrm{N}-\mathrm{O}), \mathrm{cm}^{-1}$} & \multirow{2}{*}{$\begin{array}{c}\text { MS1 } \\
, \% \\
\end{array}$} & \multirow{2}{*}{$\begin{array}{c}\lambda_{\text {top }} \\
\mathrm{nm}\end{array}$} \\
\hline & GS & MS1 & GS & MS1 & & \\
\hline $\mathrm{A}\left[\mathrm{PdCl}_{4}\right]$ & $1886 ; 1890 ; 1896$ & 1755 & $636 ; 634 ; 550 ; 540 ; 498$ & - & 1 & 365 \\
\hline $\mathrm{A}\left[\mathrm{PtCl}_{4}\right]$ & $1895 ; 1905$ & 1762 & $634 ; 548 ; 498$ & - & 1 & 300 \\
\hline $\mathrm{A}\left[\mathrm{PtCl}_{6}\right]$ & $1874 ; 1881$ & 1745 & $633 ; 538 ; 503$ & 573 & 2 & 420 \\
\hline $\mathrm{A}\left(\mathrm{ClO}_{4}\right)_{2}$ & $1874 ; 1881$ & 1747 & $637 ; 538 ; 503$ & 571 & 7 & 405 \\
\hline $\mathrm{A}\left(\mathrm{SiF}_{6}\right)^{*}$ & $1902 ; 1910$ & 1769 & $640 ; 544 ; 513 ; 503$ & $\begin{array}{l}577 ; \\
532\end{array}$ & 10 & 420 \\
\hline
\end{tabular}

Irradiation of the complexes by light in the UV-blue spectral range at low temperatures $(10 \mathrm{~K})$ results in the formation of new vibrational bands, related to the MS1 (Ru-ON isomer) (see Fig. 7, Figs. S4-S6). The $u(N-O)$ stretching vibration of MS1 appears in the range $1745-1769 \mathrm{~cm}^{-1}$ (see Table 2), which is characteristic for nitrosyl ruthenium complexes ${ }^{4,17}$. For complexes $A\left(\mathrm{ClO}_{4}\right)_{2}$ and $A\left[\mathrm{PtCl}_{6}\right]$ the $u(\mathrm{Ru}-$ $\mathrm{NO}) / \delta(\mathrm{Ru}-\mathrm{N}-\mathrm{O})$ bands related to MS1 are found at 571 and $573 \mathrm{~cm}^{-1}$, respectively, comparable to those found earlier in the $A\left(\mathrm{SiF}_{6}\right)$ complex at 577 and $532 \mathrm{~cm}^{-1}{ }^{17}$. The MS1 population is determined from the decrease of the area of $\mathrm{U}(\mathrm{N}-\mathrm{O})$ band in $\mathrm{GS}$ after isomerization $\left(100-\left(\left(\mathrm{U}(\mathrm{N}-\mathrm{O})_{\mathrm{GS}}\right.\right.\right.$, after $) /\left(\mathrm{U}(\mathrm{N}-\mathrm{O})_{\mathrm{GS}}\right.$, before)) $\cdot 100)$ and is shown in Table 2. The complex with $\mathrm{ClO}_{4}^{-}$anion shows higher MS1 population compared to the DCSs ( $7 \%$ vs. $1-2 \%$ ). The difference is most probably due to different absorption properties of the anions. In $\mathrm{A}\left[\mathrm{PdCl}_{4}\right], \mathrm{A}\left[\mathrm{PtCl}_{6}\right]$ and $\mathrm{A}\left(\mathrm{ClO}_{4}\right)_{2}$ complexes the $\mathrm{MS} 1$ can be generated by light in the range $365-470 \mathrm{~nm}$. The irradiation wavelength at which MS1 population is found to be maximal ( $\left.\lambda_{\text {top }}\right)$ is given in Table 2. Surprisingly, in the complex $A\left[\mathrm{PtCl}_{4}\right]$ the MS1 generation is possible only by irradiation in the range $300-340 \mathrm{~nm}$. This large difference in the MS1 generation wavelength as well as difference in MS1 population can be explained by the particularities of the absorption spectra of the complexes and is discussed in the UV/vis section below. Subsequent irradiation of $M S 1$ in the $A\left(\mathrm{ClO}_{4}\right)_{2}$ complex by infrared light (940 nm wavelength) results in a decrease of the $U(\mathrm{~N}-\mathrm{O}) \mathrm{MS1}$ band, an increase of the $u(\mathrm{~N}-\mathrm{O}) \mathrm{GS}$ band and the appearance of a weak $\mathrm{u}(\mathrm{N}-\mathrm{O})$ band of the Ru- $\left(\mathrm{n}^{2}-(\mathrm{NO})\right)$ isomer (MS2) with a maximum at $1494 \mathrm{~cm}^{-1}$, thereby MS1 $\rightarrow$ GS and MS1 $\rightarrow$ MS2 processes occur. The population of the MS2 isomer is about 1\%. Unfortunately, detection of MS2 in DCSs is not possible, most probably due to the low population of MS1 in these complexes. The irradiation of metastable states in all complexes by light in the spectral range 660-810 nm leads to the transition of metastable states back to the GS. The nitrosyl isomerization also affects the amine bands intensities, which slightly change after NO rotation (Fig. 7). 


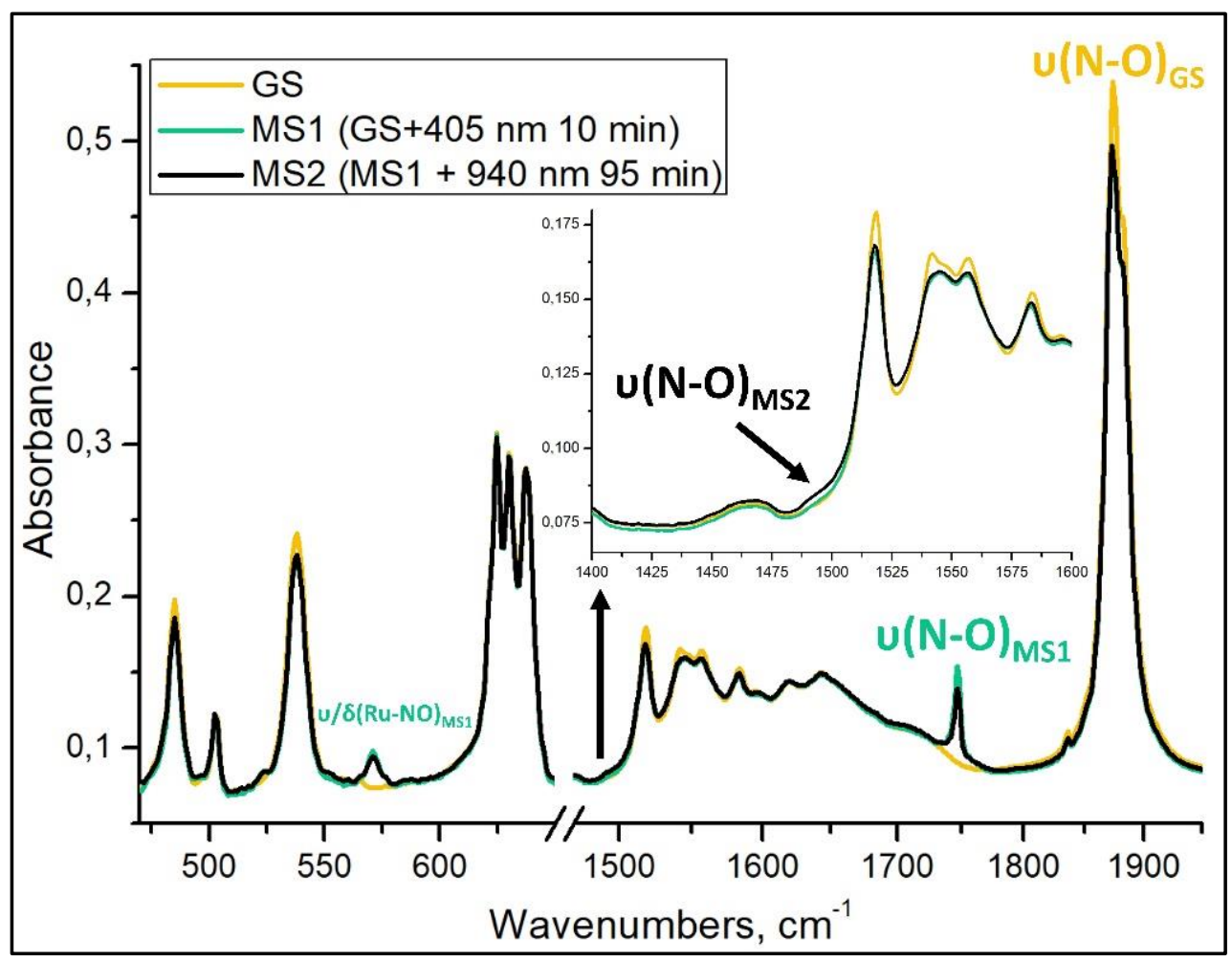

Fig. 7. IR-spectrum of $A\left(\mathrm{ClO}_{4}\right)_{2}$ at $10 \mathrm{~K}$ before (GS, yellow), after $405 \mathrm{~nm}$ irradiation (MS1, green) and after subsequent $940 \mathrm{~nm}$ irradiation (MS2, black).

Irradiation of the complexes by light in the UV-blue spectral range at higher temperatures shows, that the formation of $\mathrm{MS} 1$ in $\mathrm{A}\left(\mathrm{ClO}_{4}\right)_{2}$ is possible even at $300 \mathrm{~K}$ (Fig. 8). As was shown earlier, $\mathrm{GS}$ to MS1 isomerization is a two-step process, where the excitation of GS by the absorption of a first photon leads to the MS2 isomer formation, which then is transferred to MS1 through a second excitation by absorption of another photon, i.e. schematically a GS $\rightarrow$ MS2 $\rightarrow$ MS1 reaction occur ${ }^{4,33}$. Thus, in order to generate MS1 at room temperature a high photon flux or a long lifetime of the MS2 isomer is essential. Since in the $\mathrm{A}\left(\mathrm{SiF}_{6}\right)$ complex the MS1 can be generated at $300 \mathrm{~K}$ by rather low-intensity $\mathrm{cW}$-laser ${ }^{17}$, it indicates that the MS2 thermal stability in the $A\left(\mathrm{ClO}_{4}\right)$ complex is close to the MS2 stability of $A\left(\mathrm{SiF}_{6}\right)$ compound. In DCS complexes the MS1 can be detected only until 100-200 K. However, this is most likely due to the low achievable population of MS1 in these complexes and hence a lower sensitivity for the detection of MS1. 


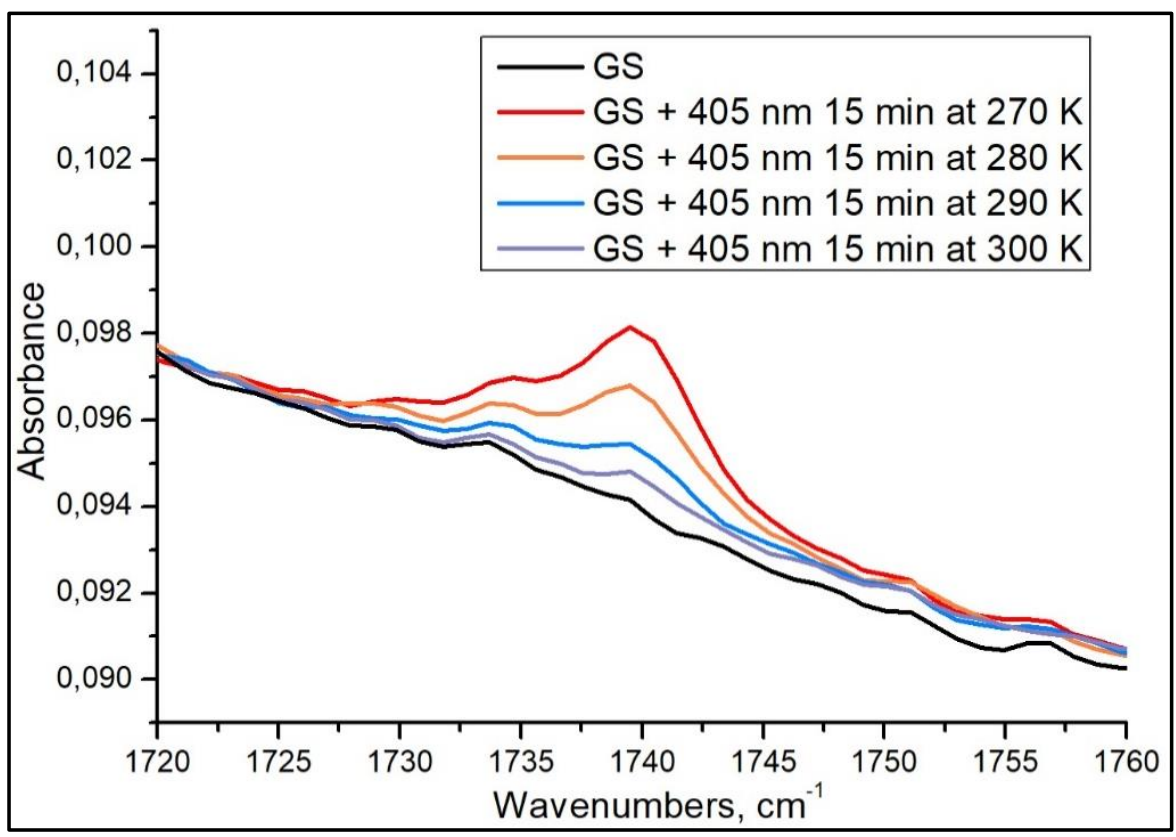

Fig. 8. Generation of $\mathrm{MS} 1$ at different temperatures in $\mathrm{A}\left(\mathrm{ClO}_{4}\right)_{2}$ complex.

\section{Photo-isomerization of nitrosyl ligand: UV/vis-spectroscopy}

First of all, the population of metastable states is determined by the absorption spectra of GS, MS1 and MS2. In terms of the GS $\rightarrow$ MS2 $\rightarrow$ MS1 mechanism, in order to achieve maximum of MS1 population, for example, cross section of GS to MS2 to MS1 reactions should be high. Hereby, strong absorption bands of GS and MS2 and weak MS1 absorption at given excitation wavelength cause higher reaction cross section of GS to MS2 to MS1 transformation, which gives higher MS1 population ${ }^{16}$. In this regard, the analysis of absorption spectra of each state (GS, MS1 and MS2) is needed to understand the efficiency of GS $\leftrightarrow \mathrm{MS} 2 \leftrightarrow \mathrm{MS1}$ equilibriums. More detailed conditions of metastable states generation are described in ${ }^{16,34}$.

$\mathrm{UV} / \mathrm{vis}$ spectra of $\mathrm{A}\left(\mathrm{ClO}_{4}\right)_{2}$ at $10 \mathrm{~K}$ exhibit broad band in low-energy range with maximum at $410 \mathrm{~nm}$ related to the charge transfer from trans-to-NO ligand (fluoride) to $\pi^{*}$ (Ru-NO) orbital (Fig. 9) ${ }^{35}$. In DCSs additional bands appears at: 600, 520 and $460 \mathrm{~nm}$ in case of $A\left[\mathrm{PdCl}_{4}\right]$ (Fig. S7); 490, 380 and $320 \mathrm{~nm}$ for $\mathrm{A}\left[\mathrm{PtCl}_{4}\right]$ (Fig. S8); $490 \mathrm{~nm}$ for $\mathrm{A}\left[\mathrm{PtCl}_{6}\right]$ (Fig. S9). The analysis of UV/vis absorption spectra of water solutions of $\mathrm{A}^{2+}, \mathrm{PdCl}_{4}{ }^{2-}, \mathrm{PtCl}_{4}{ }^{2-}$ and $\mathrm{PtCl}_{6}{ }^{2-}$ at room temperature reveal the bands mainly related to the $d-d$ and MLCT transitions in Pd and Pt anions (Fig. S10). The bands at 590 and 430 (broad) nm are found for $\mathrm{PdCl}_{4}{ }^{2+} ; 480,390$ and $330 \mathrm{~nm}$ for $\mathrm{PtCl}_{4}{ }^{2+} ; 470 \mathrm{~nm}$ for $\mathrm{PtCl}_{6}{ }^{2+}$. Thus, in DCSs there is strong overlap of absorption bands of $\mathrm{Pd}$ and $\mathrm{Pt}$ anions with the bands of Ru cation. This band overlap can explain the significant difference of MS1 population in complexes with $\mathrm{ClO}_{4}{ }^{-}$and $\mathrm{SiF}_{6}{ }^{2-}$ compared to DCSs (7-10\% vs. $1-2 \%$, see Table 2). The light absorption by the Pd or Pt anions results in a decrease of efficiency of light absorption by $\mathrm{A}^{2+}$ and consequently leads to a decrease of MS1 population through the GS $\rightarrow$ MS2 $\rightarrow$ MS1 isomerization mechanism. 


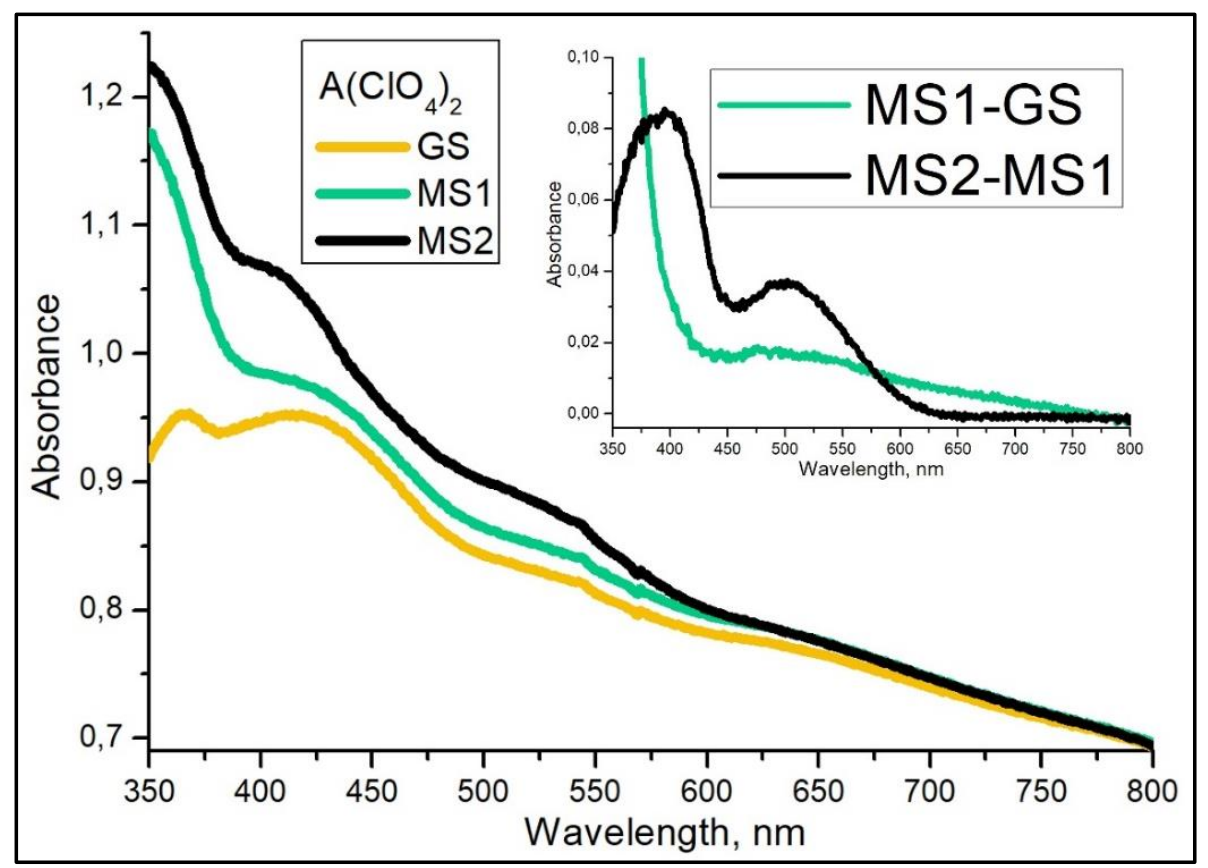

Fig. 9. UV/vis spectra of $A\left(\mathrm{ClO}_{4}\right)_{2}$ at $10 \mathrm{~K}$. Inset - the difference spectra MS1-GS and MS2-MS1.

Furthermore, neighbor atoms around of nitrosyl ligand might affect the conversion efficiency of the photo-isomerization. The influence of the structure on metastable states population was studied in work ${ }^{36}$ for $\left[\mathrm{RuNOPy}{ }_{4}\right]^{2+}\left(\mathrm{X}=\mathrm{Cl}^{-}, \mathrm{Br}^{-}\right)$complexes. The authors conclude, that an increase of intermolecular contacts between counterion and nitrosyl ligand leads to higher metastable states population. In this regard, based on available structural data of $A\left(\mathrm{SiF}_{6}\right){ }^{17}, A\left[\mathrm{PtCl}_{4}\right], A\left[\mathrm{PdCl}_{4}\right], A\left[\mathrm{PtCl}_{6}\right]$ and $\mathrm{A}\left(\mathrm{ClO}_{4}\right)_{2}$ the strongest corresponding intermolecular contacts were observed in $\mathrm{A}\left(\mathrm{SiF}_{6}\right)$ and $\mathrm{A}\left(\mathrm{ClO}_{4}\right)_{2}$ (see Table S5), which is in agreement with the higher MS1 population in these complexes (10 and $7 \%$ respectively) compared to DCS. Thus, from spectral and structural point of view the population of MS1 depends from both the nature of the counterion (electronic structure) and the structural arrangement in vicinity of the nitrosyl ligand.

The MS1 spectra of all investigated complexes are characterized by the appearance of an absorption in the range of 500-900 $\mathrm{nm}$ with a broad maximum at 400-550 $\mathrm{nm}$ (Fig. 9, S7-S9). The same MS1 band maximum at $550 \mathrm{~nm}$ was observed in $\mathrm{A}\left(\mathrm{SiF}_{6}\right)$ compound recently ${ }^{17}$. In complexes $\mathrm{A}\left(\mathrm{ClO}_{4}\right)_{2}$ and $\mathrm{A}\left[\mathrm{PtCl} \mathrm{Cl}_{6}\right]$ there is a strong increase of MS1 absorption from 400-450 nm to deeper UV, which is absent in $A\left[\mathrm{PdCl}_{4}\right]$ and $\mathrm{A}\left[\mathrm{PtCl}_{4}\right]$. Moreover, in $\mathrm{A}\left[\mathrm{PtCl}_{4}\right]$ a decrease of $\mathrm{MS1}$ absorption in 300-400 nm range is observed. Probably, from the structural point of view, the difference in absorption spectra of $A\left[\mathrm{PdCl}_{4}\right]$ and $A\left[\mathrm{PtCl}_{4}\right]$ is due to the intermolecular contacts between $\mathrm{Pd} / \mathrm{Pt}$ atoms with oxygen of NO ligand, which are 3.34/3.36 A respectively. Less MS1 absorption in the 300-400 nm range is favorable for higher MS1 population due to decrease of cross section of back reaction MS1 $\rightarrow$ GS. Indeed, in case of using $300 \mathrm{~nm}$ light irradiation the highest MS1 population was observed in $A\left[\mathrm{PtCl}_{4}\right]$. Such perceptible shift of the window for MS1 generation indicates a high sensitivity of the MS1 absorption spectrum to the change of the counterion. Nevertheless, for a full understanding of population-depopulation reactions information about MS2 spectra is needed, since photo-isomerization occurs via a two-step mechanism $\mathrm{GS} \rightarrow \mathrm{MS} 2 \rightarrow \mathrm{MS1}$. As was mentioned above in IR-spectroscopy section, MS2 spectra were obtained only for $\mathrm{A}\left(\mathrm{ClO}_{4}\right)_{2}$ complex due to the low population of MS1 in DSCs. The MS2 absorption spectra exhibits broad bands with maxima at 400 and $500 \mathrm{~nm}$ (Fig. 9). Position of the maximum at $400 \mathrm{~nm}$ is in agreement with the fact, that the highest MS1 population in $\mathrm{A}\left(\mathrm{ClO}_{4}\right)_{2}$ was achieved by the $\approx 400 \mathrm{~nm}$ light irradiation - excitation of GS is followed by efficient MS2 excitation to MS1. Presumably, the same 
MS2 behavior should exist in $\mathrm{A}\left[\mathrm{PdCl}_{6}\right]$. In cases of $\mathrm{A}\left[\mathrm{PdCl}_{4}\right]$ and $\mathrm{A}\left[\mathrm{PtCl}_{4}\right]$ the $\mathrm{MS} 2$ maxima probably shifted to UV range. Due to the presence of absorption bands of MS1 and MS2 in yellow-red range of spectrum, irradiation of these states by $660-810 \mathrm{~nm}$ light leads to GS formation. Irradiation of MS1 by $940 \mathrm{~nm}$ indicate higher probability of MS1 $\rightarrow$ MS2 reaction with respect to MS1 $\rightarrow$ GS, MS2 $\rightarrow$ GS or MS2 $\rightarrow$ MS1 processes.

\section{Photo-isomerization of nitrosyl ligand: differential scanning calorimetry}

Kinetic parameters (activation energy $\left(E_{a}\right)$ and frequency factor $\left(k_{0}\right)$ ) of the MS1 $\rightarrow$ GS reactions of the complexes were determined by differential scanning calorimetry (DSC) since the reactions are exothermic. The fit of DSC curves was made by equation of the kinetic of first order $\mathrm{dH} / \mathrm{dt}=\mathrm{H}_{\text {tot }}$ (1$\alpha) k_{0} \cdot \exp \left(-E_{a} /(R \cdot T)\right)$, where $d H / d t$ is the heat flow rate, $H_{\text {tot }}$ the total reaction enthalpy, $\alpha$ is the conversion, $R$ is the universal gas constant and $T$ is the temperature. The results of the fit are shown in Table 3. The DSC curve of $\mathrm{MS} 1 \rightarrow \mathrm{GS}$ reaction of $\mathrm{A}\left(\mathrm{ClO}_{4}\right)_{2}$ complex is shown in Fig. 10. The DSC signatures of $A\left[\mathrm{PtCl}_{6}\right]$ and $A\left[\mathrm{PtCl}_{4}\right]$ were not obtained due to the low MS1 population in the complexes and apparently small difference in MS1 and GS energies, which leads to zero thermal effect of MS1 $\rightarrow$ GS transformations. Since both parameters $E_{a}$ and $k_{0}$ determine thermal behavior of MS1, for direct comparison of the MS1 thermal stability of different complexes is more convenient to use so-called decay temperatures $\left(T_{d}\right)$. The decay temperature $T_{d}$ is the temperature calculated for a value of the rate constant of $k=10^{-3} \mathrm{~s}^{-1}$ from the Arrhenius law $k=k_{0} \cdot \exp \left(-E_{a} /(R \cdot T){ }^{37}\right.$ and roughly corresponds to the onset temperature on the DSC curve. According to the calculated $T_{d}$ (see Table 3 ), the complex salt $\mathrm{A}\left[\mathrm{PdCl}_{4}\right]$ exhibits the highest MS1 thermal stability known up to now. The thermal stability of $\mathrm{A}\left(\mathrm{ClO}_{4}\right)_{2}$ is found very high as well.

The lifetime $\tau\left(\mathrm{K}^{-1}\right)$ of $\mathrm{MS} 1$ in $\mathrm{A}\left[\mathrm{PdCl}_{4}\right], \mathrm{A}\left(\mathrm{ClO}_{4}\right)_{2}$ and $\mathrm{A}\left(\mathrm{SiF}_{6}\right)$ at $300 \mathrm{~K}$, for example, is 54,22 and 6 min respectively. Besides of the attractiveness for applications, such long lifetimes provide the possibility to study metastable isomers by common convenient methods such X-ray absorption spectroscopy or NMR without the necessity for cooling, which technically facilitates the usage of these methods. As was shown recently, high thermal stability in these complexes is due to the fluoride ligand in transposition to the nitrosyl ligand, which significantly increases the activation energy of the MS1 to GS reaction ${ }^{17,35,38}$. In general, there are several parameters, which have been reported to increase the MS1 thermal stability: higher electronegativity of a trans-ligand to NO ${ }^{17,35,38}$; higher positive charge of ruthenium nitrosyl complex ${ }^{39}$; higher lattice energy of the complex ${ }^{40}$. Supposedly, in the current case the higher thermal stability of $\mathrm{A}\left[\mathrm{PdCl}_{4}\right]$ is due to specific intermolecular and/or electrostatic interactions, which leads to the stabilization of the Ru-ON mode. To shed more light on this issue, one would need to know the exact structural configuration in the MS1 isomer, for which a photocrystallographic investigation is required, which demands high population of metastable states (at least $50 \%$ for MS1 type isomers) ${ }^{41}$. For this task the complexes with pyridine-like ligands are better candidates, since usually have higher MS1 population $4,41,42$.

Table 3. Kinetic parameters (activation energy $\left(E_{a}\right)$, frequency factor $\left(k_{0}\right)$ and decay temperature $\left(T_{d}\right)$ ) of MS1 $\rightarrow$ GS reactions determined by differential scanning calorimetry.

\begin{tabular}{|c|c|c|c|}
\hline $\begin{array}{c}\text { Complex/ } \\
\text { parameter }\end{array}$ & $E_{a}, \mathrm{~kJ} \mathrm{~mol}^{-1}$ & $\mathrm{Igk}_{0}$ & $\mathrm{~T}_{\mathrm{d}}, \mathrm{K}$ \\
\hline $\mathrm{A}\left[\mathrm{PdCl}_{4}\right]$ & $112(6)$ & $16.0(9)$ & 307 \\
\hline $\mathrm{A}\left(\mathrm{ClO}_{4}\right)_{2}$ & $104(1)$ & $15.0(2)$ & 303 \\
\hline $\mathrm{A}\left(\mathrm{SiF}_{6}\right)^{*}$ & $97.4(3)$ & $14.42(4)$ & 292 \\
\hline
\end{tabular}


\begin{tabular}{|l|l|}
\hline *Data from ${ }^{17}$ & \\
\hline
\end{tabular}

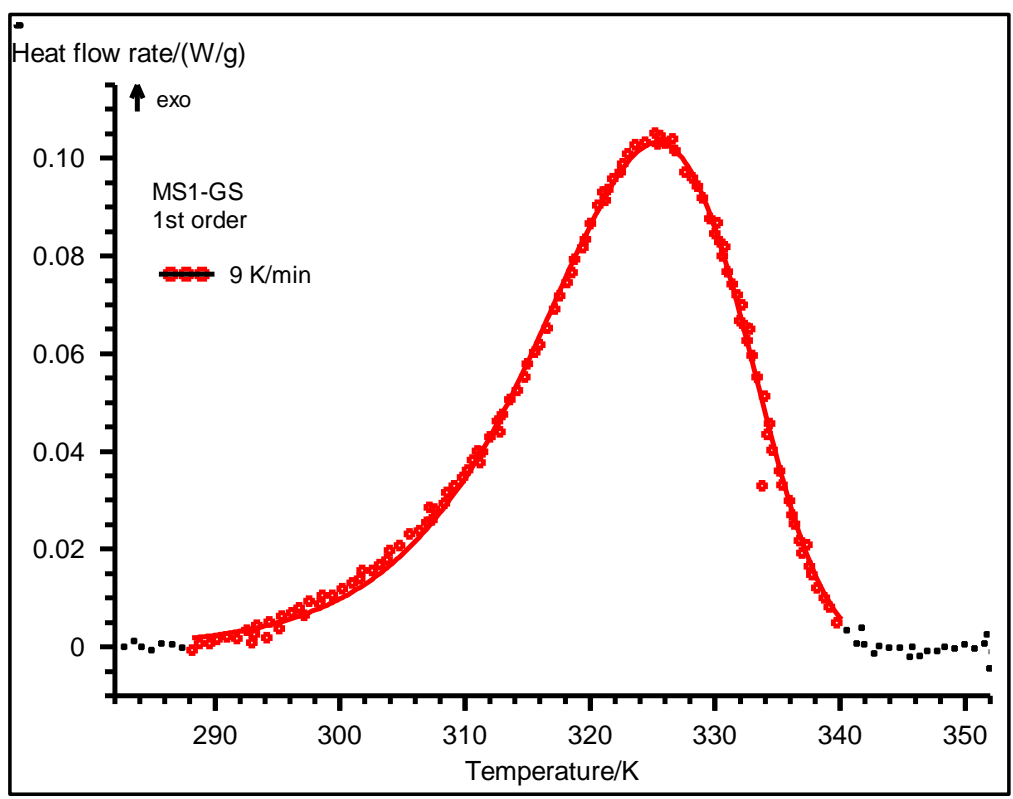

Fig. 10. DSC curve of $M S 1 \rightarrow G S$ reaction of $A\left(\mathrm{ClO}_{4}\right)_{2}$ complex and fit by kinetic of the first order reaction.

\section{Conclusions}

In current work, the complexes of the trans-[RuNO$\left.\left(\mathrm{NH}_{3}\right)_{4} \mathrm{~F}\right]^{2+}$ cation with metal-based anions $\left[\mathrm{PtCl}_{6}\right]^{2-},\left[\mathrm{PdCl}_{4}\right]^{2-}$ and $\left[\mathrm{PtCl}_{4}\right]^{2-}$, and perchlorate anion $\mathrm{ClO}_{4}^{-}$were synthesized. The characterization of all compounds was made by physical-chemical methods including single crystal X-Ray diffraction. It was shown that the trans-[RuNO $\left.\left(\mathrm{NH}_{3}\right)_{4} \mathrm{~F}\right]^{2+}$ core is suitable for the preparation of non-centrosymmetric crystals, which are formed by means of $\mathrm{N}-\mathrm{H}$...Halogen intermolecular interactions. Using spectroscopic (IR and UV/vis) and calorimetric (DSC) methods the formation of metastable NO linkage isomers Ru$\mathrm{ON}$ and $\mathrm{Ru}-\left(\eta^{2}-(\mathrm{NO})\right)$ was investigated in all complexes, and shown, the trans- $\left[\mathrm{RuNO}\left(\mathrm{NH}_{3}\right)_{4} \mathrm{~F}\right]^{2+}$ is a building block for the preparation of materials with high thermal stability of linkage isomers. Two important observations have been made from the analysis of the metastable states behavior: i) the population of the metastable states depends on the absorption properties of the counterion - an intense absorption of the counterion in the excitation wavelength range results in a decline of probability of light absorption by the ruthenium nitrosyl and consequently leads to a decline of the population of metastable state; ii) the counterion can induced a shift of the optical window for generation of metastable states - the counterion influences the position of the MS1 and MS2 absorption bands, which induces the change of the excitation wavelength, at which maximum metastable state population can be achieved. In general, these statements can be used for other metastable systems, like complexes containing nitrite $\left(\mathrm{NO}_{2}^{-}\right)$or sulfoxide-like (SO) ligands. Thus, for the design of a functional material containing a ruthenium nitrosyl block, absorption properties of the counterion must be considered. Nevertheless, the metastable states population needed to be considered together with other important properties related to metastable states, as has been shown in trans-[RuNO$\left.\left(\mathrm{NH}_{3}\right)_{4} \mathrm{~F}\right]\left[\mathrm{PdCl}_{4}\right]$ which demonstrates, that thermal stability of MS1 can be sufficiently enhanced. 


\section{Conflicts of interest}

The authors declare no competing financial interest.

\section{Acknowledgements}

The investigation was supported by Russian Basic Research Foundation (Project 19-03-00594). Artem Mikhailov is grateful for financial support from the Eiffel excellence bourse program (Grant P730329G).

\section{References}

1 W. R. Browne and B. L. Feringa, Mol. Switch. Second Ed., 2011, 1, 121-179.

2 P. Coppens, I. Novozhilova and A. Kovalevsky, Chem. Rev., 2002, 102, 861-884.

3 L. Khadeeva, W. Kaszub, M. Lorenc, I. Malfant and M. Buron-Le Cointe, Inorg. Chem., 2016, 55, 4117-4123.

4 A. A. Mikhailov, E. Wenger, G. A. Kostin and D. Schaniel, Chem. - A Eur. J., 2019, 25, 7569-7574.

5 M. Clemente-León, E. Coronado, J. R. Galán-Mascarós, C. J. Gómez-García, T. Woike and J. M. Clemente-Juan, Inorg. Chem., 2001, 40, 87-94.

6 L. A. Kushch, V. D. Sasnovskaya, E. B. Yagubskii, S. S. Khasanov, S. V. Simonov, R. P. Shibaeva, A. V. Korolev, D. V. Starichenko, A. O. Anokhin, V. Y. Irkhin and Y. N. Shvachko, Inorganica Chim. Acta, 2011, 378, 169-173.

7 R. Ababei, Y. G. Li, O. Roubeau, M. Kalisz, N. Bréfuel, C. Coulon, E. Harté, X. Liu, C. Mathonière and R. Clérac, New J. Chem., 2009, 33, 1237-1248.

8 V. A. Kopotkov, V. D. Sasnovskaya, D. V. Korchagin, R. B. Morgunov, S. M. Aldoshin, S. V. Simonov, L. V. Zorina, D. Schaniel, T. Woike and E. B. Yagubskii, CrystEngComm, 2015, 17, 3866-3876.

9 L. A. Kushch, L. S. Kurochkina, E. B. Yagubskii, G. V. Shilov, S. M. Aldoshin, V. A. Emel'yanov, Y. N. Shvachko, V. S. Mironov, D. Schaniel, T. Woike, C. Carbonera and C. Mathonière, Eur. J. Inorg. Chem., 2006, 4074-4085.

10 L. A. Kushch, S. Golhen, O. Cador, E. B. Yagubskii, M. A. II'In, D. Schaniel, T. Woike and L. Ouahab, J. Clust. Sci., 2006, 17, 303-315.

11 L. A. Kushch, G. V. Shilov, M. A. II'In, T. Woike, D. Schaniel and E. B. Yagubskii, Russ. Chem. Bull., 2008, 57, 557-560.

12 L. A. Kushch, V. A. Emel'yanov, S. Golhen, O. Cador, D. Schaniel, T. Woike, L. Ouahab and E. B. Yagubskii, Inorganica Chim. Acta, 2009, 362, 2279-2282.

13 L. A. Kushch, V. D. Sasnovskaya, E. B. Yagubskii, A. I. Dmitriev, R. B. Morgunov, V. A. Emel'yanov and T. Woike, Russ. Chem. Bull., 2011, 60, 1078-1084.

14 D. Schaniel, T. Woike, L. Kushch and E. Yagubskii, Chem. Phys., 2007, 340, 211-216.

15 L. A. Kushch, E. B. Yagubskii, A. I. Dmitriev, R. B. Morgunov, V. A. Emel'Yanov, A. R. Mustafina, A. T. Gubaidullin, V. A. Burilov, S. E. Solovieva, D. Schaniel and T. Woike, Phys. B Condens. Matter, 2010, 405, 30-33.

D. Schaniel and T. Woike, Phys. Chem. Chem. Phys., 2009, 11, 4298-4359. 
17 A. Mikhailov, V. Vuković, C. Kijatkin, E. Wenger, M. Imlau, T. Woike, G. Kostin and D. Schaniel, Acta Crystallogr. Sect. B Struct. Sci. Cryst. Eng. Mater., 2019, 75, 1152-1163.

G. M. Sheldrick, Acta Crystallogr. Sect. A Found. Adv., 2015, 71, 3-8.

19 O. V. Dolomanov, L. J. Bourhis, R. J. Gildea, J. A. K. Howard and H. Puschmann, J. Appl. Crystallogr., 2009, 42, 339-341.

F. L. Hirshfeld, Theor. Chim. Acta, 1977, 44, 129-138.

M. A. Spackman and D. Jayatilaka, CrystEngComm, 2009, 11, 19-32.

J. H. Enemark and R. D. Feltham, Coord. Chem. Rev., 1974, 13, 339-406.

23 J. Akl, C. Billot, P. G. Lacroix, I. Sasaki, S. Mallet-Ladeira, I. Malfant, R. Arcos-Ramos, M. Romero and N. Farfán, New J. Chem., 2013, 37, 3518-3527.

Y. Y. Li, J. Q. Wang, P. F. Liu, H. Lin, L. Chen and L. M. Wu, RSC Adv., 2017, 7, 8082-8089.

25 J. Xiong, K. Kubo, S. F. Lü, M. Li and T. Nakamura, Dalt. Trans., 2018, 47, 14001-14007.

26 S. Debrus, H. Ratajczak, J. Venturini, N. Pinçon, J. Baran, J. Barycki, T. Glowiak and A. Pietraszko, Synth. Met., 2002, 127, 99-104.

27 H. Athmani, C. Kijatkin, R. Benali-Cherif, S. Pillet, D. Schaniel, M. Imlau, N. Benali-Cherif and E.-E. Bendeif, Acta Crystallogr. Sect. A Found. Adv., 2019, 75, 107-114.

28 A. C. Merkle, A. B. McQuarters and N. Lehnert, Dalt. Trans., 2012, 41, 8047.

29 J. A. Güida, M. A. Ramos, O. E. Piro and P. J. Aymonino, J. Mol. Struct., 2002, 609, 39-46.

30 M. Weidemann, S. Sievertsen and H. Homborg, Zeitschrift für Anorg. und Allg. Chemie, 1998, 624, 909-918.

31 P. C. Ford, Coord. Chem. Rev., 1970, 5, 75-99.

32 F. Zapata and C. García-Ruiz, Spectrochim. Acta - Part A Mol. Biomol. Spectrosc., 2018, $189,535-542$.

33 J. Sanz García, F. Alary, M. Boggio-Pasqua, I. M. Dixon, I. Malfant and J.-L. Heully, Inorg. Chem., 2015, 54, 8310-8318.

34 L. E. Hatcher, J. M. Skelton, M. R. Warren and P. R. Raithby, Acc. Chem. Res., 2019, 52, 1079-1088.

35 R. D. Yamaletdinov and I. L. Zilberberg, Eur. J. Inorg. Chem., 2017, 23, 2951-2954.

36 B. Cormary, S. Ladeira, K. Jacob, P. G. Lacroix, T. Woike, D. Schaniel and I. Malfant, Inorg. Chem., 2012, 51, 7492-7501.

37 Y. Morioka, A. Ishikawa, H. Tomizawa and E. Miki, J. Chem. Soc. Dalt. Trans., 2000, 54, 781-786.

38 G. A. Kostin, A. A. Mikhailov, N. V Kuratieva, D. P. Pishchur and A. N. Makhinya, New J. Chem., 2018, 42, 18928-18934.

39 V. Vorobyev, A. A. Mikhailov, V. Y. Komarov, A. N. Makhinya and G. A. Kostin, New J. Chem., 2020, 44, 4762-4771.

40 H. Zöllner, W. Krasser, T. Woike and S. Haussühl, Chem. Phys. Lett., 1989, 161, 497-501. 
41 B. Cormary, I. Malfant, M. Buron-Le Cointe, L. Toupet, B. Delley, D. Schaniel, N. Mockus, T. Woike, K. Fejfarová, V. Petř́ček and M. Dušek, Acta Crystallogr. Sect. B Struct. Sci., 2009, 65, 612-623.

42 G. A. Kostin, A. O. Borodin, A. A. Mikhailov, N. V. Kuratieva, B. A. Kolesov, D. P. Pishchur, T. Woike and D. Schaniel, Eur. J. Inorg. Chem., 2015, 29, 4905-4913. 


\section{Supporting information}

\section{The impact of counterion on metastable states properties in nitrosyl ruthenium complexes}

Artem A. Mikhailov*a, Vladislav Yu. Komarovª, Aleksandr S. Sukhikha, Denis P. Pishchura, Dominik Schaniel ${ }^{\mathrm{b}}$ and Gennadiy A. Kostin ${ }^{\mathrm{a}}$

${ }^{a}$ Nikolaev Institute of Inorganic Chemistry, Siberian Branch of the Russian Academy of Sciences, 3 Acad. Lavrentiev Avenue, Novosibirsk 630090, Russian Federation

b Université de Lorraine, CNRS, CRM2, UMR 7036, Nancy 54000, France

Email: amikhailov@niic.nsc.ru

Table S1. Experimental and refinement details.

\begin{tabular}{|c|c|c|c|c|}
\hline Complex & {$\left[\mathrm{RuNO}\left(\mathrm{NH}_{3}\right)_{4} \mathrm{~F}\right]\left[\mathrm{PtCl}_{6}\right]$} & {$\left[\mathrm{RuNO}\left(\mathrm{NH}_{3}\right)_{4} \mathrm{~F}\right]\left[\mathrm{PdCl}_{4}\right]$} & {$\left[\mathrm{RuNO}\left(\mathrm{NH}_{3}\right)_{4} \mathrm{~F}\right]\left[\mathrm{PtCl}_{4}\right]$} & {$\left[\mathrm{RuNO}\left(\mathrm{NH}_{3}\right)_{4} \mathrm{~F}\right]\left(\mathrm{ClO}_{4}\right)_{2}$} \\
\hline Empirical formula & $\mathrm{Cl}_{6} \mathrm{FH}_{12} \mathrm{~N}_{5} \mathrm{OPtRu}$ & $\mathrm{Cl}_{4} \mathrm{FH}_{12} \mathrm{~N}_{5} \mathrm{OPdRu}$ & $\mathrm{Cl}_{4} \mathrm{H}_{12} \mathrm{FN}_{5} \mathrm{OPtRu}$ & $\mathrm{Cl}_{2} \mathrm{H}_{12} \mathrm{FN}_{5} \mathrm{O}_{9} \mathrm{Ru}$ \\
\hline Formula weight & 626.01 & 466.42 & 555.11 & 417.12 \\
\hline Temperature/K & $150(2)$ & $150(2)$ & $150(2)$ & $150(2)$ \\
\hline Crystal system & orthorhombic & orthorhombic & orthorhombic & triclinic \\
\hline Space group & $\mathrm{P} 2_{1} 2_{1} 2_{1}$ & $\mathrm{Cmc2}_{1}$ & $\mathrm{Cmc2}_{1}$ & $\mathrm{P} \overline{1}$ \\
\hline$a / \AA ̊$ & $7.0583(5)$ & $8.1541(3)$ & $8.1354(13)$ & $8.0038(5)$ \\
\hline $\mathrm{b} / \AA$ & $8.7624(6)$ & $17.4696(10)$ & $17.5637(18)$ & $11.8995(5)$ \\
\hline$c / \AA ̊$ & $22.0421(14)$ & $8.1730(5)$ & $8.1749(8)$ & $13.8054(8)$ \\
\hline$\alpha /^{\circ}$ & 90 & 90 & 90 & $70.720(2)$ \\
\hline$\beta /^{\circ}$ & 90 & 90 & 90 & $86.091(2)$ \\
\hline$\gamma /{ }^{\circ}$ & 90 & 90 & 90 & $88.040(2)$ \\
\hline Volume $/ \AA^{3}$ & $1363.25(16)$ & $1164.23(11)$ & $1168.1(2)$ & $1238.12(12)$ \\
\hline Z & 4 & 4 & 4 & 4 \\
\hline$\rho_{\text {calc }} / \mathrm{cm}^{3}$ & 3.050 & 2.661 & 3.157 & 2.238 \\
\hline$\mu / \mathrm{mm}^{-1}$ & 12.528 & 3.745 & 14.157 & 1.759 \\
\hline$F(000)$ & 1152.0 & 888.0 & 1016.0 & 824.0 \\
\hline Crystal size $/ \mathrm{mm}^{3}$ & $0.07 \times 0.03 \times 0.03$ & $0.17 \times 0.08 \times 0.02$ & $0.11 \times 0.08 \times 0.03$ & $0.1 \times 0.08 \times 0.04$ \\
\hline Radiation & $\operatorname{MoK} \alpha(\lambda=0.71073)$ & $\operatorname{MoK} \alpha(\lambda=0.71073)$ & $\operatorname{MoK} \alpha(\lambda=0.71073)$ & $\operatorname{MoK} \alpha(\lambda=0.71073)$ \\
\hline $\begin{array}{c}2 \Theta \text { range for data } \\
\text { collection } /{ }^{\circ}\end{array}$ & 3.696 to 61.3 & 4.664 to 59.27 & 4.638 to 52.69 & 3.936 to 66.314 \\
\hline Index ranges & $\begin{array}{r}-9 \leq h \leq 9 \\
-12 \leq k \leq 12 \\
-31 \leq 1 \leq 30\end{array}$ & $\begin{array}{l}-11 \leq h \leq 10, \\
-24 \leq k \leq 23, \\
-11 \leq 1 \leq 11\end{array}$ & $\begin{array}{l}-10 \leq h \leq 9 \\
-21 \leq k \leq 20 \\
-10 \leq 1 \leq 10\end{array}$ & $\begin{array}{l}-12 \leq h \leq 12 \\
-18 \leq k \leq 18 \\
-20 \leq 1 \leq 21\end{array}$ \\
\hline Reflections collected & 44736 & 11486 & 2669 & 24099 \\
\hline Independent reflections & $\begin{array}{c}4053\left[R_{\text {int }}=0.0534\right. \\
\left.R_{\text {sigma }}=0.0340\right]\end{array}$ & $\begin{array}{c}1750\left[R_{\text {int }}=0.0400,\right. \\
\left.R_{\text {sigma }}=0.0290\right]\end{array}$ & $\begin{array}{c}1253\left[R_{\text {int }}=0.0465,\right. \\
\left.R_{\text {sigma }}=0.0880\right]\end{array}$ & $\begin{array}{c}24099\left[R_{\text {int }}=0.0373,\right. \\
\left.R_{\text {sigma }}=0.0448\right]\end{array}$ \\
\hline Data/restraints/parameters & $4053 / 0 / 137$ & $1750 / 1 / 73$ & $1253 / 7 / 72$ & $24099 / 0 / 334$ \\
\hline Goodness-of-fit on $\mathrm{F}^{2}$ & 1.056 & 1.053 & 0.833 & 1.080 \\
\hline Final $R$ indexes $[1>=2 \sigma(I)]$ & $\begin{aligned} \mathrm{R}_{1} & =0.0251 \\
\mathrm{WR} & =0.0340\end{aligned}$ & $\begin{aligned} R_{1} & =0.0200 \\
W R_{2} & =0.0359\end{aligned}$ & $\begin{array}{r}\mathrm{R}_{1}=0.0336 \\
\mathrm{wR}_{2}=0.0629\end{array}$ & $\begin{aligned} R_{1} & =0.0385 \\
w R_{2} & =0.0988\end{aligned}$ \\
\hline Final $R$ indexes [all data] & $\begin{aligned} R_{1} & =0.0329 \\
w R_{2} & =0.0359\end{aligned}$ & $\begin{aligned} R_{1} & =0.0220 \\
W R_{2} & =0.0371\end{aligned}$ & $\begin{aligned} R_{1} & =0.0444 \\
W R_{2} & =0.0685\end{aligned}$ & $\begin{aligned} R_{1} & =0.0586 \\
w R_{2} & =0.1088\end{aligned}$ \\
\hline $\begin{array}{l}\text { Largest diff. peak/hole / e } \\
\AA^{-3}\end{array}$ & $1.08 /-1.78$ & $0.41 /-0.41$ & $1.23 /-1.33$ & $0.81 /-1.01$ \\
\hline Flack parameter & $-0.011(3)$ & $-0.07(3)$ & $0.020(12)$ & - \\
\hline
\end{tabular}


Table S2. Selected bond lengths $(\AA ̊)$ in obtained complexes.

\begin{tabular}{|c|c|c|c|c|c|}
\hline \multicolumn{5}{|c|}{ Distance/complex } \\
\hline \multicolumn{2}{|c|}{$\mathrm{A}\left[\mathrm{PtCl}_{4}\right]$} & \multicolumn{2}{c|}{$\mathrm{A}\left[\mathrm{PdCl}{ }_{4}\right]$} & \multicolumn{2}{c|}{$\mathrm{A}\left[\mathrm{PtCl}{ }_{6}\right]$} \\
\hline $\mathrm{Pt}-\mathrm{Cl} 1$ & $2.310(6)$ & $\mathrm{Pd}-\mathrm{Cl} 1$ & $2.312(1)$ & $\mathrm{Pt}-\mathrm{Cl} 1$ & $2.330(1)$ \\
\hline $\mathrm{Pt}-\mathrm{Cl} 2$ & $2.302(2)$ & $\mathrm{Pd}-\mathrm{Cl} 2$ & $2.298(1)$ & $\mathrm{Pt}-\mathrm{Cl} 2$ & $2.314(2)$ \\
\hline $\mathrm{Pt}-\mathrm{Cl} 3$ & $3.339(6)$ & $\mathrm{Pd}-\mathrm{Cl} 3$ & $2.344(2)$ & $\mathrm{Pt}-\mathrm{Cl} 3$ & $2.321(1)$ \\
\hline $\mathrm{Pt}-\mathrm{Cl} 4$ & $2.302(2)$ & $\mathrm{Pd}-\mathrm{Cl} 4$ & $2.298(1)$ & $\mathrm{Pt}-\mathrm{Cl} 4$ & $2.328(2)$ \\
\hline & & & & $\mathrm{Pt}-\mathrm{Cl} 5$ & $2.323(2)$ \\
\hline & & & & $\mathrm{Pt}-\mathrm{Cl} 16$ & $2.313(2)$ \\
\hline
\end{tabular}

Table S3. Bond lengths $(\AA)$ in the $\mathrm{ClO}_{4}{ }^{-}$anions of the $\mathrm{A}\left(\mathrm{ClO}_{4}\right)_{2}$.

\begin{tabular}{|l|l|l|l|l|l|l|l|}
\hline \multicolumn{7}{|c|}{ Bond/ Distance } \\
\hline $\mathrm{Cl} 1-03$ & $1.427(2)$ & $\mathrm{Cl} 2-07$ & $1.449(3)$ & $\mathrm{Cl}-011$ & $1.438(3)$ & $\mathrm{Cl} 4-015$ & $1.409(2)$ \\
\hline $\mathrm{Cl} 1-04$ & $1.441(3)$ & $\mathrm{Cl} 2-08$ & $1.434(2)$ & $\mathrm{Cl}-012$ & $1.432(3)$ & $\mathrm{Cl} 4-016$ & $1.438(3)$ \\
\hline $\mathrm{Cl} 1-05$ & $1.433(3)$ & $\mathrm{Cl} 2-09$ & $1.426(3)$ & $\mathrm{Cl} 3-013$ & $1.434(3)$ & $\mathrm{Cl} 4-017$ & $1.440(3)$ \\
\hline $\mathrm{Cl} 1-06$ & $1.449(3)$ & $\mathrm{Cl} 2-010$ & $1.428(4)$ & $\mathrm{Cl}-014$ & $1.443(2)$ & $\mathrm{Cl} 4-018$ & $1.441(3)$ \\
\hline
\end{tabular}

Table S4. Found hydrogen bond lengths $(\AA ̊)$ and angles $\left({ }^{\circ}\right)$.

\begin{tabular}{|c|c|c|c|c|c|}
\hline \multicolumn{6}{|c|}{ Distance, angle/complex } \\
\hline \multicolumn{3}{|c|}{$\mathrm{A}\left[\mathrm{PdCl}_{4}\right]$} & \multicolumn{3}{|c|}{$\mathrm{A}\left[\mathrm{PtCl}_{4}\right]$} \\
\hline $\mathrm{N} 1-\mathrm{H} \cdots \mathrm{Cl} 2$ & 2.844 & 112.0 & $\mathrm{~N} 1-\mathrm{H} \cdots \mathrm{Cl} 2$ & 2.534 & 156.9 \\
\hline $\mathrm{N} 1-\mathrm{H} \cdots \mathrm{Cl} 3$ & 2.526 & 171.6 & $\mathrm{~N} 1-\mathrm{H} \cdots \mathrm{Cl} 2$ & 2.813 & 119.7 \\
\hline $\mathrm{N} 1-\mathrm{H} \cdots \mathrm{Cl} 2$ & 2.528 & 151.3 & $\mathrm{~N} 1-\mathrm{H} \cdots \mathrm{Cl} 3$ & 2.614 & 163.1 \\
\hline $\mathrm{N} 3-\mathrm{H} \cdots \mathrm{Cl} 2$ & 2.804 & 145.8 & $\mathrm{~N} 3-\mathrm{H} \cdots \mathrm{Cl} 1$ & 2.572 & 158.3 \\
\hline $\mathrm{N} 3-\mathrm{H} \cdots \mathrm{Cl} 3$ & 2.637 & 138.5 & $\mathrm{~N} 3-\mathrm{H} \cdots \mathrm{Cl} 2$ & 2.854 & 121.7 \\
\hline $\mathrm{N} 3-\mathrm{H} \cdots \mathrm{Cl} 2$ & 2.908 & 149.8 & $\mathrm{~N} 3-\mathrm{H} \cdots \mathrm{Cl} 3$ & 2.547 & 159.3 \\
\hline $\mathrm{N} 3-\mathrm{H} \cdots \mathrm{Cl} 1$ & 2.912 & 114.9 & $\mathrm{~N} 1-\mathrm{H} \cdots \mathrm{F} 1$ & 2.148 & 142.2 \\
\hline $\mathrm{N} 3-\mathrm{H} \cdots \mathrm{Cl} 2$ & 2.458 & 169.9 & & & \\
\hline $\mathrm{N} 1-\mathrm{H} \cdots \mathrm{F} 1$ & 2.046 & 149.1 & & & \\
\hline \multicolumn{3}{|c|}{$\mathrm{A}\left(\mathrm{ClO}_{4}\right)_{2}$} & \multicolumn{3}{|c|}{$\mathrm{A}\left[\mathrm{PtCl}_{6}\right]$} \\
\hline $\mathrm{N} 1-\mathrm{H} \cdots \mathrm{O} 13$ & 2.365 & 128.1 & $\mathrm{~N} 1-\mathrm{H} \cdots \mathrm{Cl} 4$ & 2.886 & 127.9 \\
\hline $\mathrm{N} 1-\mathrm{H} \cdots \mathrm{O} 7$ & 2.422 & 144.1 & $\mathrm{~N} 1-\mathrm{H} \cdots \mathrm{Cl} 6$ & 2.649 & 152.9 \\
\hline $\mathrm{N} 1-\mathrm{H} \cdots \mathrm{O} 15$ & 2.484 & 114.3 & $\mathrm{~N} 1-\mathrm{H} \cdots \mathrm{Cl} 6$ & 2.927 & 122.6 \\
\hline $\mathrm{N} 1-\mathrm{H} \cdots \mathrm{O} 9$ & 2.639 & 117.3 & $\mathrm{~N} 1-\mathrm{H} \cdots \mathrm{Cl} 3$ & 2.787 & 140.1 \\
\hline $\mathrm{N} 1-\mathrm{H} \cdots \mathrm{O} 14$ & 2.613 & 139.4 & $\mathrm{~N} 1-\mathrm{H} \cdots \mathrm{Cl} 2$ & 2.759 & 133.1 \\
\hline 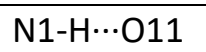 & 2.617 & 116.8 & $\mathrm{~N} 1-\mathrm{H} \cdots \mathrm{Cl} 3$ & 2.916 & 126.9 \\
\hline $\mathrm{N} 2-\mathrm{H} \cdots \mathrm{O} 8$ & 2.701 & 134.0 & $\mathrm{~N} 1-\mathrm{H} \cdots \mathrm{Cl} 5$ & 2.776 & 148.2 \\
\hline $\mathrm{N} 2-\mathrm{H} \cdots \mathrm{O} 7$ & 2.265 & 163.6 & $\mathrm{~N} 2-\mathrm{H} \cdots \mathrm{Cl} 1$ & 2.774 & 139.2 \\
\hline $\mathrm{N} 2-\mathrm{H} \cdots \mathrm{O} 8$ & 2.243 & 138.4 & $\mathrm{~N} 2-\mathrm{H} \cdots \mathrm{Cl} 4$ & 2.669 & 152.5 \\
\hline $\mathrm{N} 2-\mathrm{H} \cdots \mathrm{O} 6$ & 2.537 & 132.3 & $\mathrm{~N} 2-\mathrm{H} \cdot \mathrm{Cl} 5$ & 2.701 & 131.1 \\
\hline $\mathrm{N} 2-\mathrm{H} \cdots \mathrm{O} 3$ & 2.648 & 130.4 & $\mathrm{~N} 2-\mathrm{H} \cdots \mathrm{Cl} 5$ & 2.433 & 176.4 \\
\hline $\mathrm{N} 2-\mathrm{H} \cdots 13$ & 2.395 & 116.1 & $\mathrm{~N} 3-\mathrm{H} \cdots \mathrm{Cl} 1$ & 2.672 & 151.3 \\
\hline $\mathrm{N} 3-\mathrm{H} \cdots \mathrm{O} 6$ & 2.591 & 124.1 & $\mathrm{~N} 3-\mathrm{H} \cdots \mathrm{Cl} 2$ & 2.515 & 172.4 \\
\hline
\end{tabular}




\begin{tabular}{|c|c|c|c|c|c|}
\hline $\mathrm{N} 3-\mathrm{H} \cdots \mathrm{O} 8$ & 2.463 & 142.1 & $\mathrm{~N} 3-\mathrm{H} \cdots \mathrm{Cl} 6$ & 2.819 & 126.6 \\
\hline $\mathrm{N} 3-\mathrm{H} \cdots \mathrm{O} 10$ & 2.417 & 145.6 & $\mathrm{~N} 4-\mathrm{H} \cdots \mathrm{Cl} 3$ & 2.600 & 156.2 \\
\hline $\mathrm{N} 3-\mathrm{H} \cdots \mathrm{O} 4$ & 2.218 & 142.9 & $\mathrm{~N} 4-\mathrm{H} \cdots \mathrm{Cl} 2$ & 2.884 & 82.9 \\
\hline $\mathrm{N} 3-\mathrm{H} \cdots \mathrm{O} 18$ & 2.652 & 116.3 & $\mathrm{~N} 4-\mathrm{H} \cdots \mathrm{Cl} 1$ & 2.926 & 101.5 \\
\hline $\mathrm{N} 3-\mathrm{H} \cdots \mathrm{O} 16$ & 2.212 & 146.4 & $\mathrm{~N} 4-\mathrm{H} \cdots \mathrm{Cl} 6$ & 2.530 & 158.5 \\
\hline $\mathrm{N} 4-\mathrm{H} \cdots \mathrm{O} 4$ & 2.632 & 132.4 & $\mathrm{~N} 4-\mathrm{H} \cdots \mathrm{F} 1$ & 2.399 & 114.6 \\
\hline $\mathrm{N} 4-\mathrm{H} \cdots \mathrm{O} 3$ & 2.365 & 144.5 & & & \\
\hline $\mathrm{N} 4-\mathrm{H} \cdots \mathrm{O} 18$ & 2.317 & 145.3 & & & \\
\hline $\mathrm{N} 4-\mathrm{H} \cdots \mathrm{O} 13$ & 2.476 & 110.0 & & & \\
\hline $\mathrm{N} 4-\mathrm{H} \cdots \mathrm{O} 11$ & 2.272 & 152.7 & & & \\
\hline $\mathrm{N} 4-\mathrm{H} \cdots \mathrm{O} 13$ & 2.535 & 105.7 & & & \\
\hline $\mathrm{N} 6-\mathrm{H} \cdots \mathrm{O} 18$ & 2.371 & 166.6 & & & \\
\hline $\mathrm{N} 6-\mathrm{H} \cdots \mathrm{O} 12$ & 2.409 & 118.9 & & & \\
\hline $\mathrm{N} 6-\mathrm{H} \cdots \mathrm{O} 16$ & 2.130 & 155.3 & & & \\
\hline $\mathrm{N} 7-\mathrm{H} \cdots \mathrm{O} 5$ & 2.203 & 150.3 & & & \\
\hline $\mathrm{N} 7-\mathrm{H} \cdots \mathrm{O} 12$ & 2.092 & 158.5 & & & \\
\hline $\mathrm{N} 7-\mathrm{H} \cdots \mathrm{O} 6$ & 2.173 & 172.6 & & & \\
\hline $\mathrm{N} 7-\mathrm{H} \cdots \mathrm{O} 5$ & 2.691 & 121.2 & & & \\
\hline $\mathrm{N} 8-\mathrm{H} \cdots \mathrm{O} 9$ & 2.244 & 143.2 & & & \\
\hline $\mathrm{N} 8-\mathrm{H} \cdots \mathrm{O} 12$ & 2.631 & 100.6 & & & \\
\hline $\mathrm{N} 8-\mathrm{H} \cdots \mathrm{O} 12$ & 2.595 & 103.7 & & & \\
\hline $\mathrm{N} 8-\mathrm{H} \cdots \mathrm{O} 7$ & 2.208 & 171.9 & & & \\
\hline $\mathrm{N} 8-\mathrm{H} \cdots \mathrm{O} 6$ & 2.377 & 145.2 & & & \\
\hline $\mathrm{N} 8-\mathrm{H} \cdots \mathrm{O} 4$ & 2.344 & 153.3 & & & \\
\hline $\mathrm{N} 9-\mathrm{H} \cdots \mathrm{O} 17$ & 2.679 & 119.7 & & & \\
\hline $\mathrm{N} 9-\mathrm{H} \cdots \mathrm{O} 12$ & 2.255 & 135.2 & & & \\
\hline $\mathrm{N} 9-\mathrm{H} \cdots \mathrm{O} 7$ & 2.523 & 137.8 & & & \\
\hline $\mathrm{N} 9-\mathrm{H} \cdots \mathrm{O} 17$ & 2.111 & 164.6 & & & \\
\hline $\mathrm{N} 1-\mathrm{H} \cdots \mathrm{F} 1$ & 1.992 & 176.6 & & & \\
\hline $\mathrm{N} 6-\mathrm{H} \cdots \mathrm{F} 2$ & 2.160 & 156.0 & & & \\
\hline $\mathrm{N} 9-\mathrm{H} \cdots \mathrm{F} 2$ & 2.128 & 159.2 & & & \\
\hline & & & & & \\
\hline
\end{tabular}

Table S5. Intermolecular contacts shorter than the sum of the van der Waals radii (contacting atoms are underlined).

\begin{tabular}{|c|c|c|c|c|c|c|c|c|c|}
\hline \multicolumn{10}{|c|}{ Contact length $(\AA ̊) /$ complex } \\
\hline \multicolumn{2}{|c|}{$\mathrm{A}\left(\mathrm{SiF}_{6}\right)$} & \multicolumn{2}{|c|}{$\mathrm{A}\left[\mathrm{PtCl}_{6}\right]$} & \multicolumn{2}{|c|}{$\mathrm{A}\left[\mathrm{PdCl}_{4}\right]$} & \multicolumn{2}{|c|}{$\mathrm{A}\left[\mathrm{PtCl}_{4}\right]$} & \multicolumn{2}{|c|}{$\mathrm{A}\left(\mathrm{ClO}_{4}\right)_{2} *$} \\
\hline $\mathrm{NO} \cdots \mathrm{NH}_{3}$ & 2.66 & $\mathrm{NO} \cdots \mathrm{Cl}$ & 3.12 & $\mathrm{NO} \cdots \mathrm{Cl}$ & 3.19 & $\mathrm{NO} \cdots \mathrm{Cl}$ & 3.17 & NO $\cdots O$ & $2.91 ; 2.92$ \\
\hline $\mathrm{NQ} \cdots \mathrm{F}$ & 2.66 & $\mathrm{NO} \cdots \mathrm{Cl}$ & 3.17 & $\mathrm{NO} \cdots \mathrm{Cl}$ & 3.19 & $\mathrm{NO} \cdots \mathrm{Cl}$ & 3.17 & NO $\cdots O$ & $3.04 ; 3.01$ \\
\hline $\mathrm{NQ} \cdots \mathrm{F}$ & 2.86 & $\mathrm{NO} \cdots \mathrm{Cl}$ & 3.17 & & & $\underline{\mathrm{NO}} \cdots \mathrm{Cl}$ & 3.29 & NO $\cdots O$ & $2.94 ; 3.01$ \\
\hline NO $\cdots F$ & 2.97 & $\mathrm{NO} \cdots \mathrm{Cl}$ & 3.30 & & & $\mathrm{NO} \cdots \mathrm{Cl}$ & 3.29 & NO $\cdots O$ & $2.97 ; 3.04$ \\
\hline
\end{tabular}




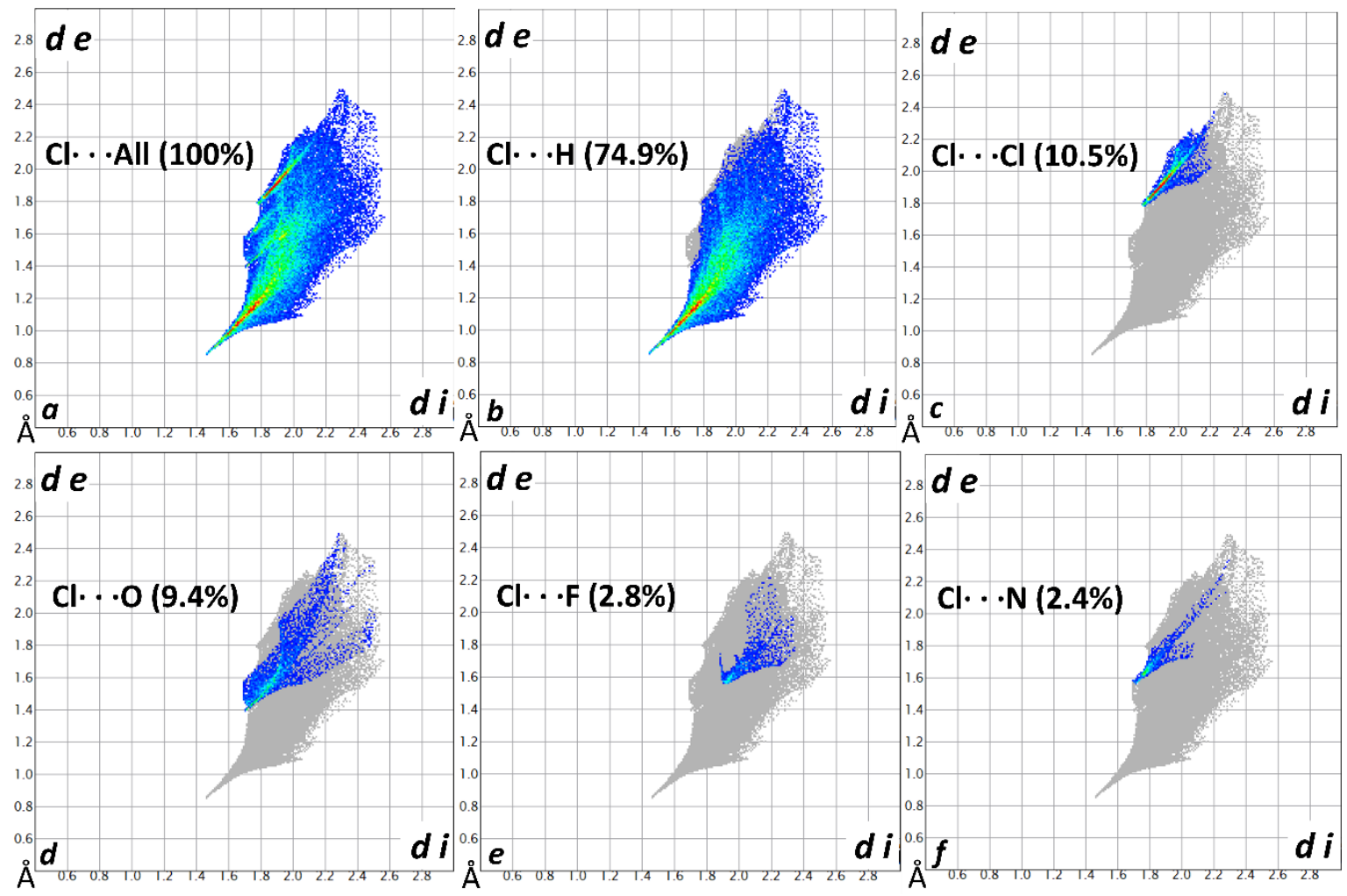

Fig. S1. The two-dimensional fingerprints of Hirshfeld surface of the $\left[\mathrm{PtCl}_{6}\right]^{2-}$ in $A\left[\mathrm{PtCl}_{6}\right]$.

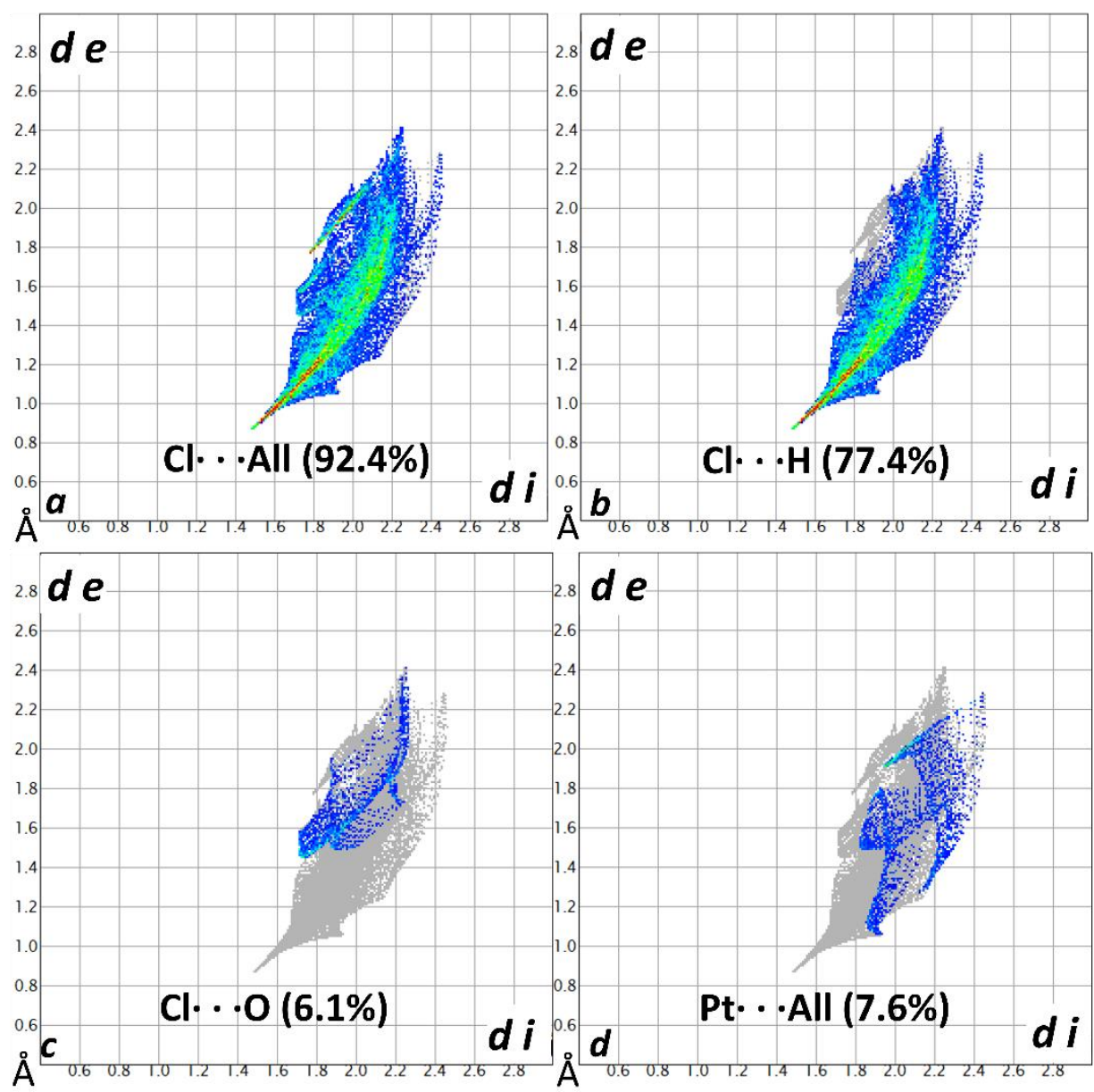

Fig. S2. The two-dimensional fingerprints of Hirshfeld surface of the $\left[\mathrm{PdCl}_{4}\right]^{2-}$ in $\mathrm{A}\left[\mathrm{PdCl}_{4}\right]$. 

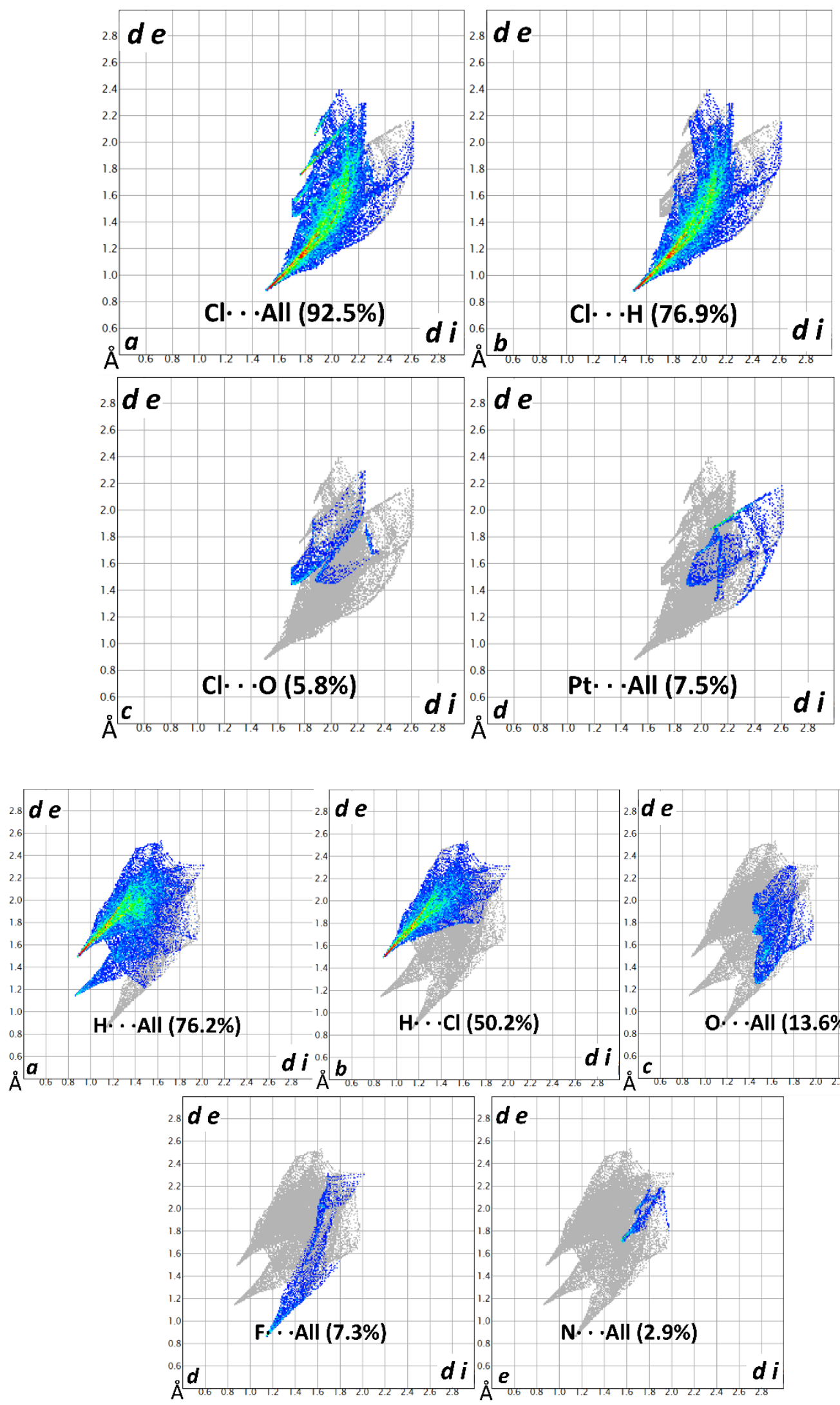

Fig. S3. The two-dimensional fingerprints of Hirshfeld surface of the $\left[\mathrm{PtCl}_{4}\right]^{2-}$ (top panels) and $\left[\mathrm{RuNO}\left(\mathrm{NH}_{3}\right)_{4} \mathrm{~F}\right]^{2+}$ (bottom panels) in $\mathrm{A}\left[\mathrm{PtCl}_{4}\right]$. 


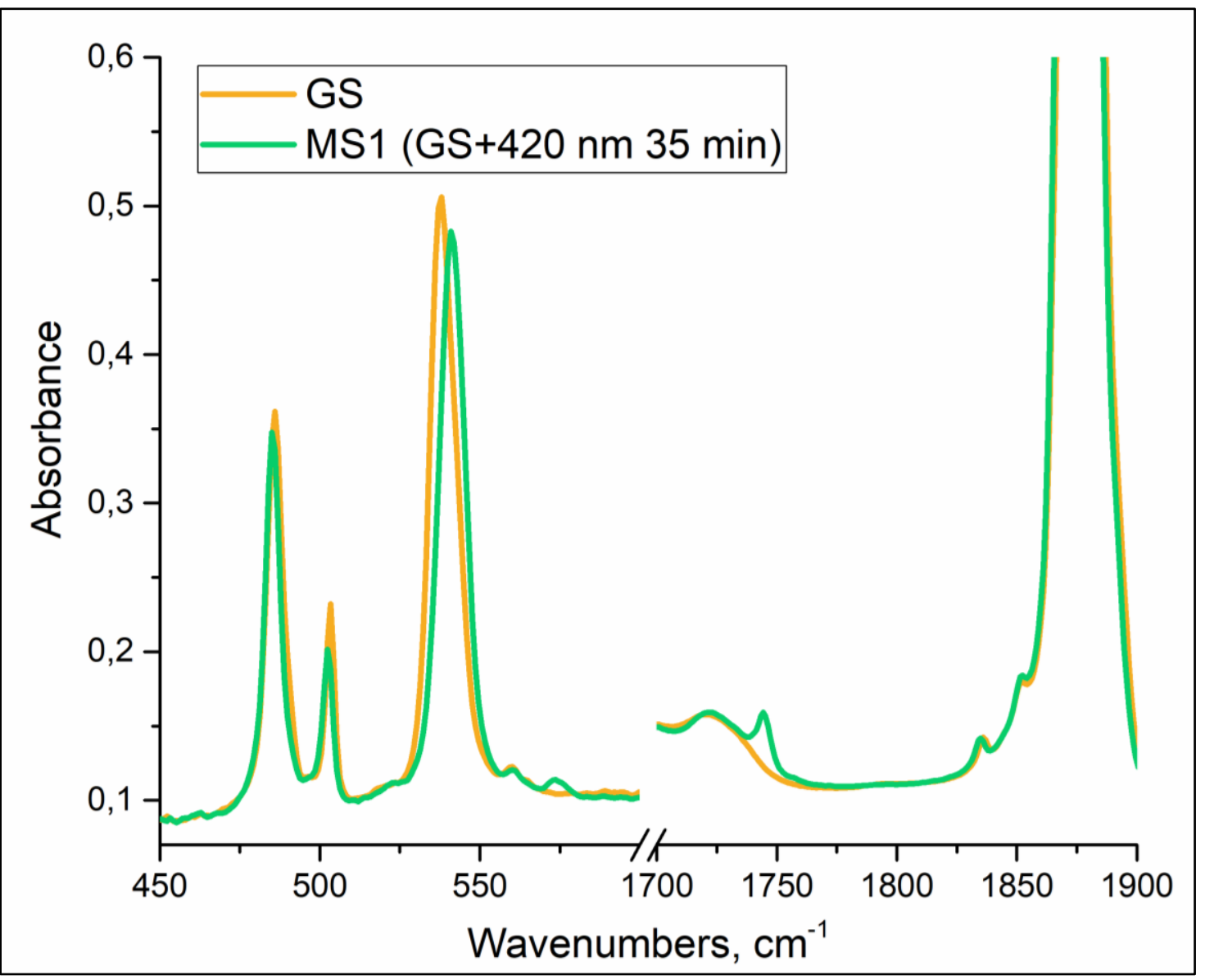

Fig. S4. IR-spectrum of $A\left[\mathrm{PtCl}_{6}\right]$ at $10 \mathrm{~K}$ before (GS, yellow) and after $420 \mathrm{~nm}$ irradiation (MS1, green).

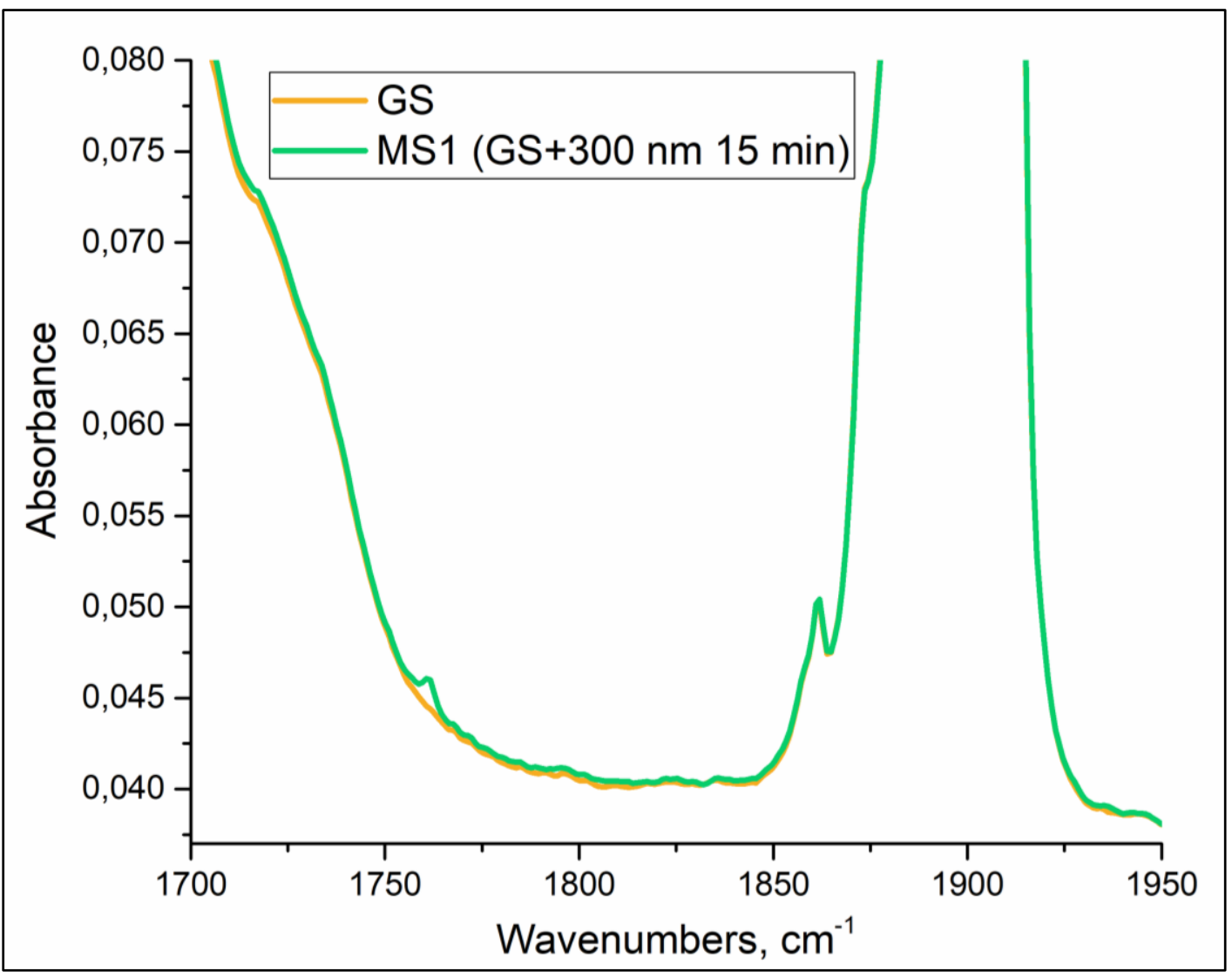


Fig. S5. IR-spectrum of $A\left[\mathrm{PtCl}_{4}\right]$ at $10 \mathrm{~K}$ before (GS, yellow) and after $300 \mathrm{~nm}$ irradiation (MS1, green).

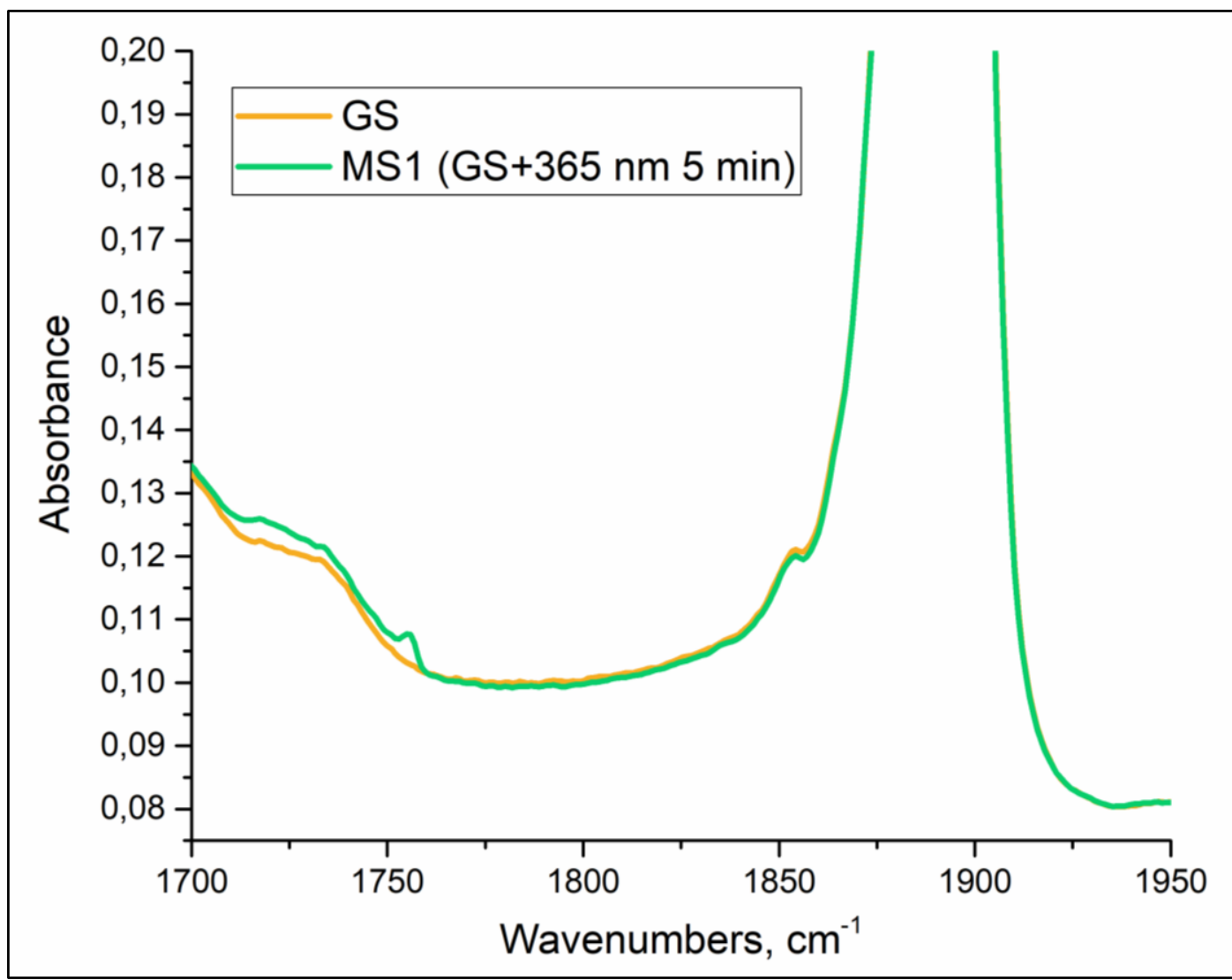

Fig. S6. IR-spectrum of $A\left[\mathrm{PdCl}_{4}\right]$ at $10 \mathrm{~K}$ before (GS, yellow) and after $365 \mathrm{~nm}$ irradiation (MS1, green).

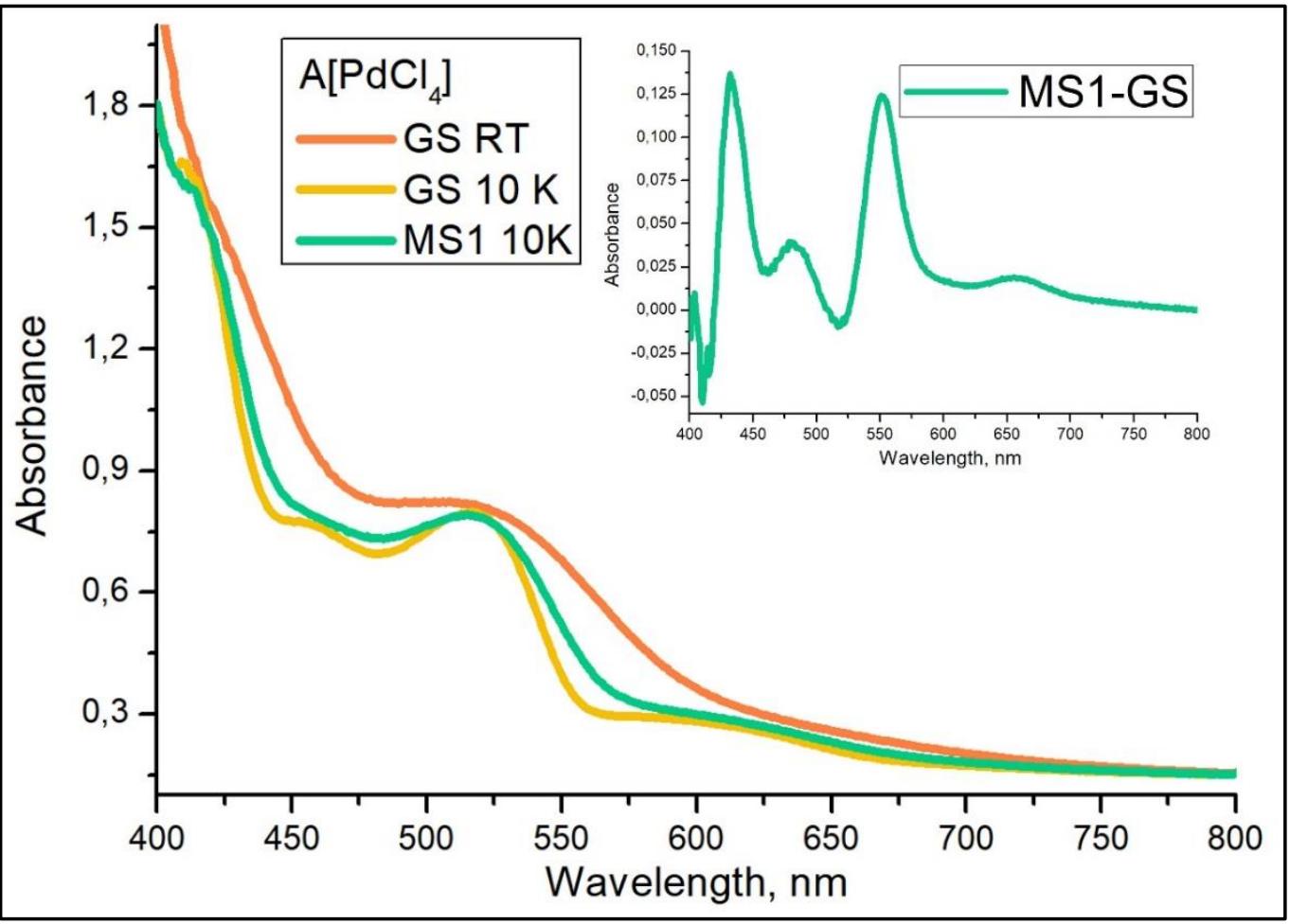


Fig. S7. UV/vis spectra of $\mathrm{A}\left[\mathrm{PdCl}_{4}\right]$ in $\mathrm{KBr}$ at room temperature (orange), $10 \mathrm{~K}$ (yellow) and after $\mathrm{MS1}$ generation at $10 \mathrm{~K}$ (green).

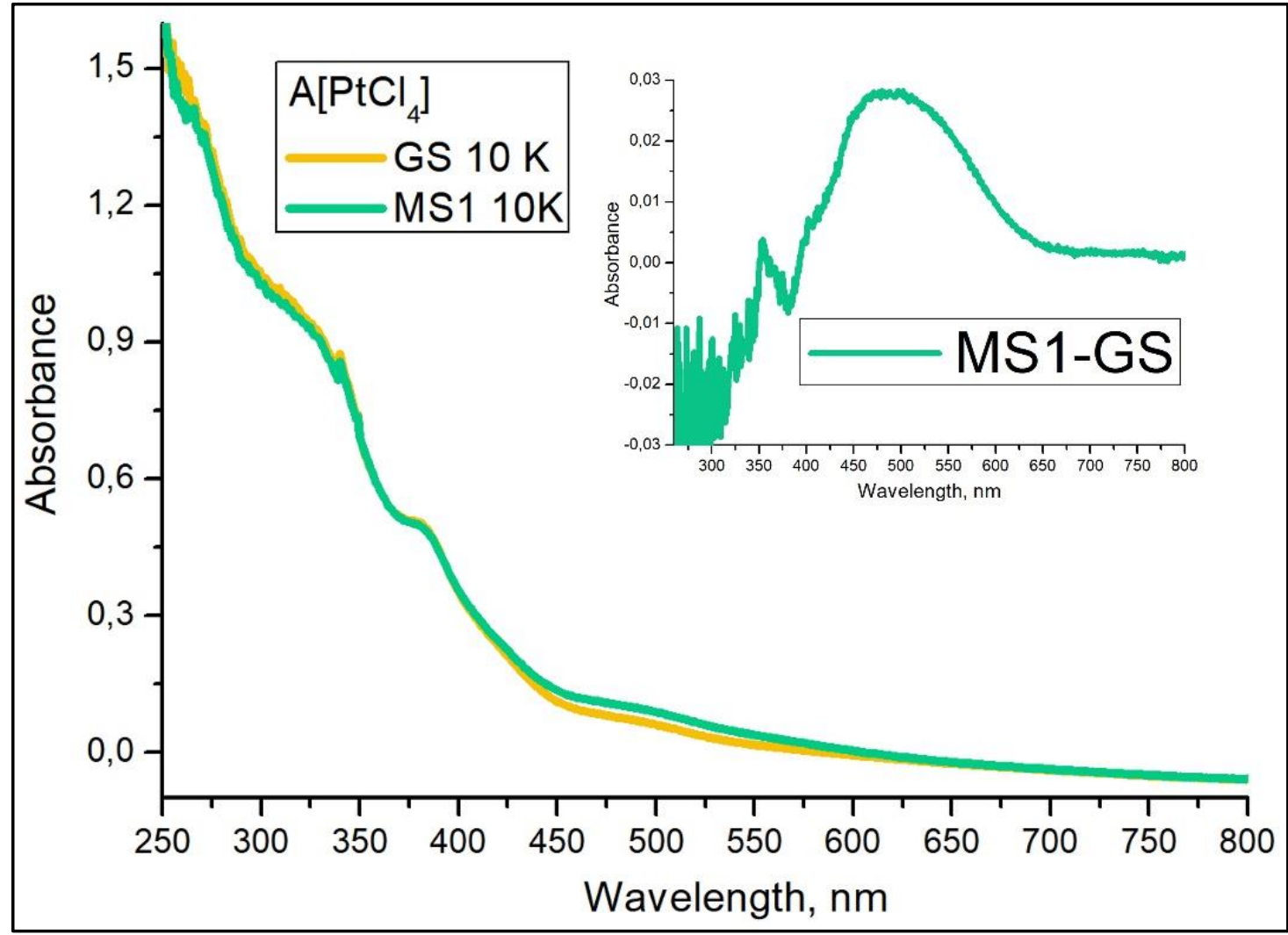

Fig. S8. UV/vis spectra of $\mathrm{A}\left[\mathrm{PtCl}_{4}\right]$ in $\mathrm{KBr}$ at $10 \mathrm{~K}$ (yellow) and after MS1 generation at $10 \mathrm{~K}$ (green).

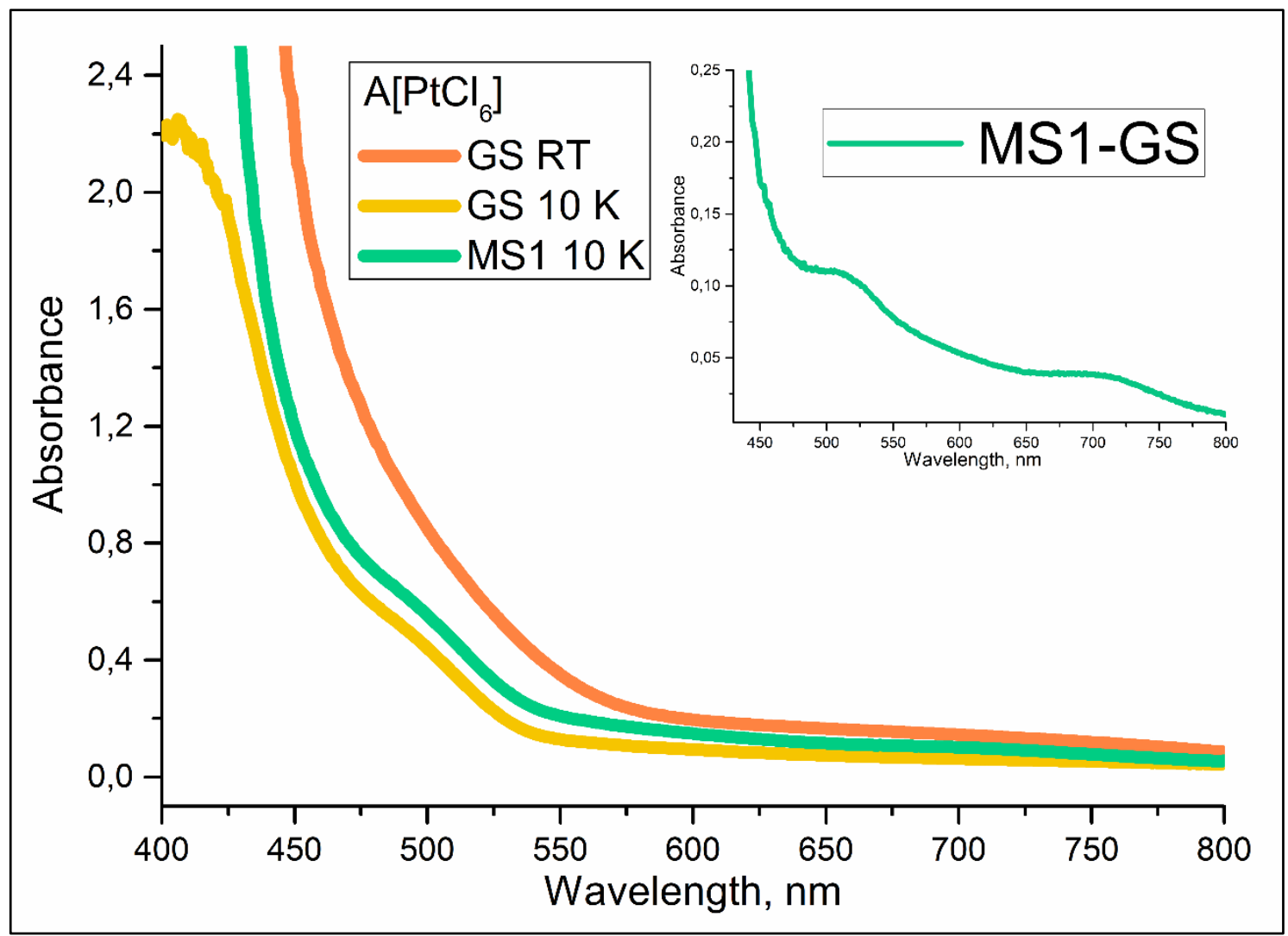


Fig. S9. UV/vis spectra of $\mathrm{A}\left[\mathrm{PtCl}_{6}\right]$ in $\mathrm{KBr}$ at room temperature (orange), $10 \mathrm{~K}$ (yellow) and after MS1 generation at $10 \mathrm{~K}$ (green).

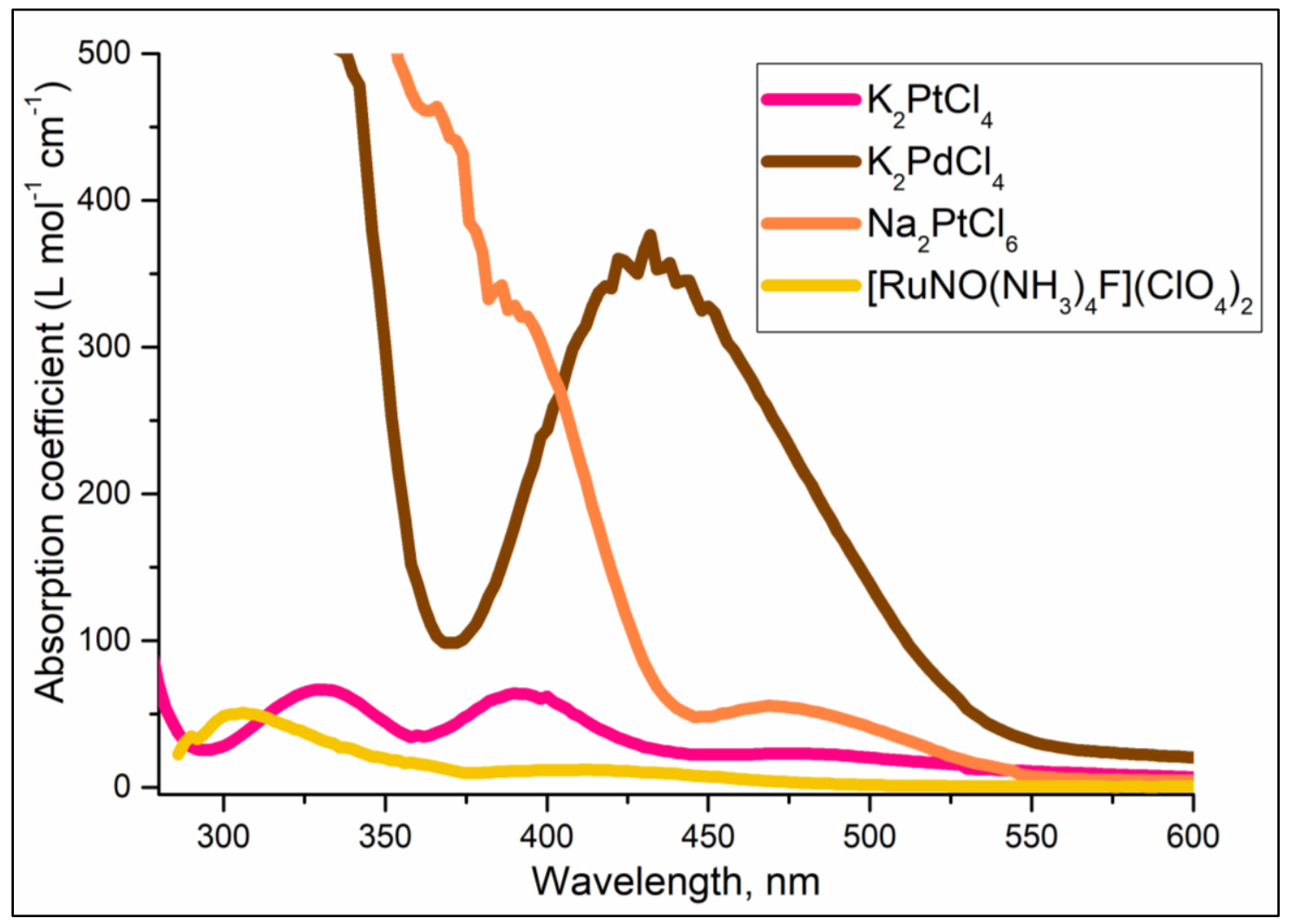

Fig. S10. UV/vis spectra of water solutions of $\mathrm{K}_{2} \mathrm{PtCl}_{4}$ (pink), $\mathrm{K}_{2} \mathrm{PdCl}_{4}$ (brown), $\mathrm{Na}_{2} \mathrm{PtCl}_{6}$ (orange) and $\left[\mathrm{RuNO}\left(\mathrm{NH}_{3}\right)_{4} \mathrm{~F}\right]\left(\mathrm{ClO}_{4}\right)_{2}$ (yellow). 